Cochrane Database of Systematic Reviews

\title{
Comprehensive geriatric assessment for older people admitted to a surgical service (Review)
}

Eamer G, Taheri A, Chen SS, Daviduck Q, Chambers T, Shi X, Khadaroo RG

Eamer G, Taheri A, Chen SS, Daviduck Q, Chambers T, Shi X, Khadaroo RG.

Comprehensive geriatric assessment for older people admitted to a surgical service.

Cochrane Database of Systematic Reviews 2018, Issue 1. Art. No.: CD012485.

DOI: 10.1002/14651858.CD012485.pub2.

www.cochranelibrary.com 
TABLE OF CONTENTS

HEADER 1

ABSTRACT

PLAIN LANGUAGE SUMMARY

SUMMARY OF FINDINGS

BACKGROUND

OBJECTIVES

METHODS

RESULTS

Figure 1.

Figure 2.

Figure 3.

DISCUSSION

AUTHORS' CONCLUSIONS

ACKNOWLEDGEMENTS

REFERENCES

CHARACTERISTICS OF STUDIES

DATA AND ANALYSES

Analysis 1.1. Comparison 1 Geriatric care versus control, Outcome 1 Mortality.

Analysis 1.2. Comparison 1 Geriatric care versus control, Outcome 2 Discharge to an increased level of care.

Analysis 1.3. Comparison 1 Geriatric care versus control, Outcome 3 Length of stay.

Analysis 1.4. Comparison 1 Geriatric care versus control, Outcome 4 Re-admission.

Analysis 1.5. Comparison 1 Geriatric care versus control, Outcome 5 Major complication.

Analysis 1.6. Comparison 1 Geriatric care versus control, Outcome 6 Major complication - delirium. APPENDICES

WHAT'S NEW

CONTRIBUTIONS OF AUTHORS

DECLARATIONS OF INTEREST

SOURCES OF SUPPORT

DIFFERENCES BETWEEN PROTOCOL AND REVIEW

NOTES

INDEX TERMS 
[Intervention Review]

\section{Comprehensive geriatric assessment for older people admitted to a surgical service}

Gilgamesh Eamer ${ }^{1}$, Amir Taheri ${ }^{1}$, Sidian S Chen ${ }^{1}$, Quinn Daviduck ${ }^{1}$, Thane Chambers ${ }^{2}$, Xinzhe Shi³, Rachel G Khadaroo ${ }^{4}$

1Department of Surgery, University of Alberta, Edmonton, Canada. 2University of Alberta, Edmonton, Canada. ${ }^{3}$ Center for the Advancement of Minimally Invasive Surgery, Department of Surgery, Royal Alexandra Hospital, Edmonton, Canada. ${ }^{4}$ Department of Surgery, Divisions of General Surgery and Critical Care Medicine, University of Alberta, Edmonton, Canada

Contact address: Rachel G Khadaroo, Department of Surgery, Divisions of General Surgery and Critical Care Medicine, University of Alberta, 2D3.79 WMC, University of Alberta Hospital, 8440-112th Street NW, Edmonton, AB, T6G 2B7, Canada. khadaroo@ualberta.ca.

Editorial group: Cochrane Effective Practice and Organisation of Care Group.

Publication status and date: Edited (no change to conclusions), published in Issue 3, 2018.

Citation: Eamer G, Taheri A, Chen SS, Daviduck Q, Chambers T, Shi X, Khadaroo RG. Comprehensive geriatric assessment for older people admitted to a surgical service. Cochrane Database of Systematic Reviews 2018, Issue 1. Art. No.: CD012485. DOI: 10.1002/14651858.CD012485.pub2.

Copyright @ 2018 The Cochrane Collaboration. Published by John Wiley \& Sons, Ltd.

\section{A B S T R A C T}

\section{Background}

Aging populations are at increased risk of postoperative complications. New methods to provide care for older people recovering from surgery may reduce surgery-related complications. Comprehensive geriatric assessment (CGA) has been shown to improve some outcomes for medical patients, such as enabling them to continue living at home, and has been proposed to have positive impacts for surgical patients. CGA is a coordinated, multidisciplinary collaboration that assesses the medical, psychosocial and functional capabilities and limitations of an older person, with the goal of establishing a treatment plan and long-term follow-up.

\section{Objectives}

To assess the effectiveness of CGA interventions compared to standard care on the postoperative outcomes of older people admitted to hospital for surgical care.

\section{Search methods}

We searched CENTRAL, MEDLINE, Embase, PsycINFO, CINAHL and two clinical trials registers on 13 January 2017. We also searched grey literature for additional citations.

\section{Selection criteria}

Randomized trials of people undergoing surgery aged 65 years and over comparing CGA with usual surgical care and reporting any of our primary (mortality and discharge to an increased level of care) or secondary (length of stay, re-admission, total cost and postoperative complication) outcomes. We excluded studies if the participants did not receive a complete CGA, did not undergo surgery, and if the study recruited participants aged less than 65 years or from a setting other than an acute care hospital.

\section{Data collection and analysis}

Two review authors independently screened, assessed risk of bias, extracted data and assessed certainty of evidence from identified articles. We expressed dichotomous treatment effects as risk ratio (RR) with 95\% confidence intervals and continuous outcomes as mean difference (MD). 


\section{Main results}

We included eight randomised trials, seven recruited people recovering from a hip fracture $(N=1583)$ and one elective surgical oncology trial $(\mathrm{N}=260)$, conducted in North America and Europe. For two trials CGA was done pre-operatively and postoperatively for the remaining. Six trials had adequate randomization, five had low risk of performance bias and four had low risk of detection bias. Blinding of participants was not possible. All eight trials had low attrition rates and seven reported all expected outcomes.

CGA probably reduces mortality in older people with hip fracture (RR $0.85,95 \% \mathrm{Cl} 0.68$ to $1.05 ; 5$ trials, 1316 participants, $\mathrm{I}^{2}=0 \%$; moderatecertainty evidence). The intervention reduces discharge to an increased level of care (RR $0.71,95 \% \mathrm{Cl} 0.55$ to $0.92 ; 5$ trials, 941 participants, $\mathrm{I}^{2}=0 \%$; high-certainty evidence).

Length of stay was highly heterogeneous, with mean difference between participants allocated to the intervention and the control groups ranging between -12.8 and 8.3 days. CGA probably leads to slightly reduced length of stay ( 4 trials, 841 participants, moderatecertainty evidence). The intervention probably makes little or no difference in re-admission rates (RR 1.00, $95 \% \mathrm{Cl} 0.76$ to $1.32 ; 3$ trials, 741 participants, $I^{2}=37 \%$; moderate-certainty evidence).

CGA probably slightly reduces total cost (1 trial, 397 participants, moderate-certainty evidence). The intervention may make little or no difference for major postoperative complications ( 2 trials, 579 participants, low-certainty evidence) and delirium rates (RR $0.75,95 \% \mathrm{Cl}$ 0.60 to $0.94,3$ trials, 705 participants, $I^{2}=0 \%$; low-certainty evidence).

\section{Authors' conclusions}

There is evidence that CGA can improve outcomes in people with hip fracture. There are not enough studies to determine when CGA is most effective in relation to surgical intervention or if CGA is effective in surgical patients presenting with conditions other than hip fracture.

\section{PLAIN LANGUAGE SUMMARY}

\section{Does special assessment of older people getting surgery improve their recovery after surgery?}

\section{What is the aim of this review?}

Our aim was to find out whether an assessment, called comprehensive geriatric assessment (CGA), of people who are aged 65 years and over improves how well they do after surgery. CGA involves several healthcare professionals and addresses the medical illness, physical decline and social factors that slow recovery.

\section{Key messages}

We found that older people with hip fracture who received CGA were less likely to die and more likely to return home. There were not enough high quality studies in other patient groups to determine if CGA is useful for them.

\section{What was studied in the review?}

The world's population is getting older; more and more people are now over the age of 65 years and are at increased risk of complications after surgery, which include infection, heart attacks and even death. CGA is known to lower complications in hospitalized older people, but no reviews looked specifically into older people who have had surgery. We conducted this review to address that gap. We compared people who received CGA either before ( 2 studies) or after surgery ( 6 studies) to people who received traditional postoperative care from their surgeon.

\section{What are the main results of the review?}

We included eight studies conducted in North America and Europe. Seven studies recruited people with broken hips (1583 participants) and one involved people who had cancers removed (260 participants).

We found that older people who received CGA probably have lower risk of dying, and that after discharge, were more likely to return to the same location they lived in before hospital admission. Older people who received the intervention probably stayed in hospital for fewer days, although we cannot be sure by how long, because results from studies varied too much. Both those who received the intervention, and those who did not, were re-admitted to hospital a similar number of times. It probably costs a bit less to provide care when older people receive CGA. As for complications after surgery, the results from the different studies varied a lot so we cannot be sure whether CGA causes more complications.

\section{How up-to-date is this review?}

We last searched for new studies on 13 January 2017. 
SUMMARY OF FINDINGS

Summary of findings for the main comparison. Comprehensive geriatric assessment for older people admitted to a surgical service

Comprehensive geriatric assessment for older people admitted to a surgical service

Patient or population: Improving outcomes in older adult people admitted to a surgical service.

Setting: Acute hospital or rehabilitation hospital following acute admission; Canada, Netherlands, Norway, UK, USA, Spain, and Sweden.

Intervention: Comprehensive geriatric assessment.

Comparison: Control.

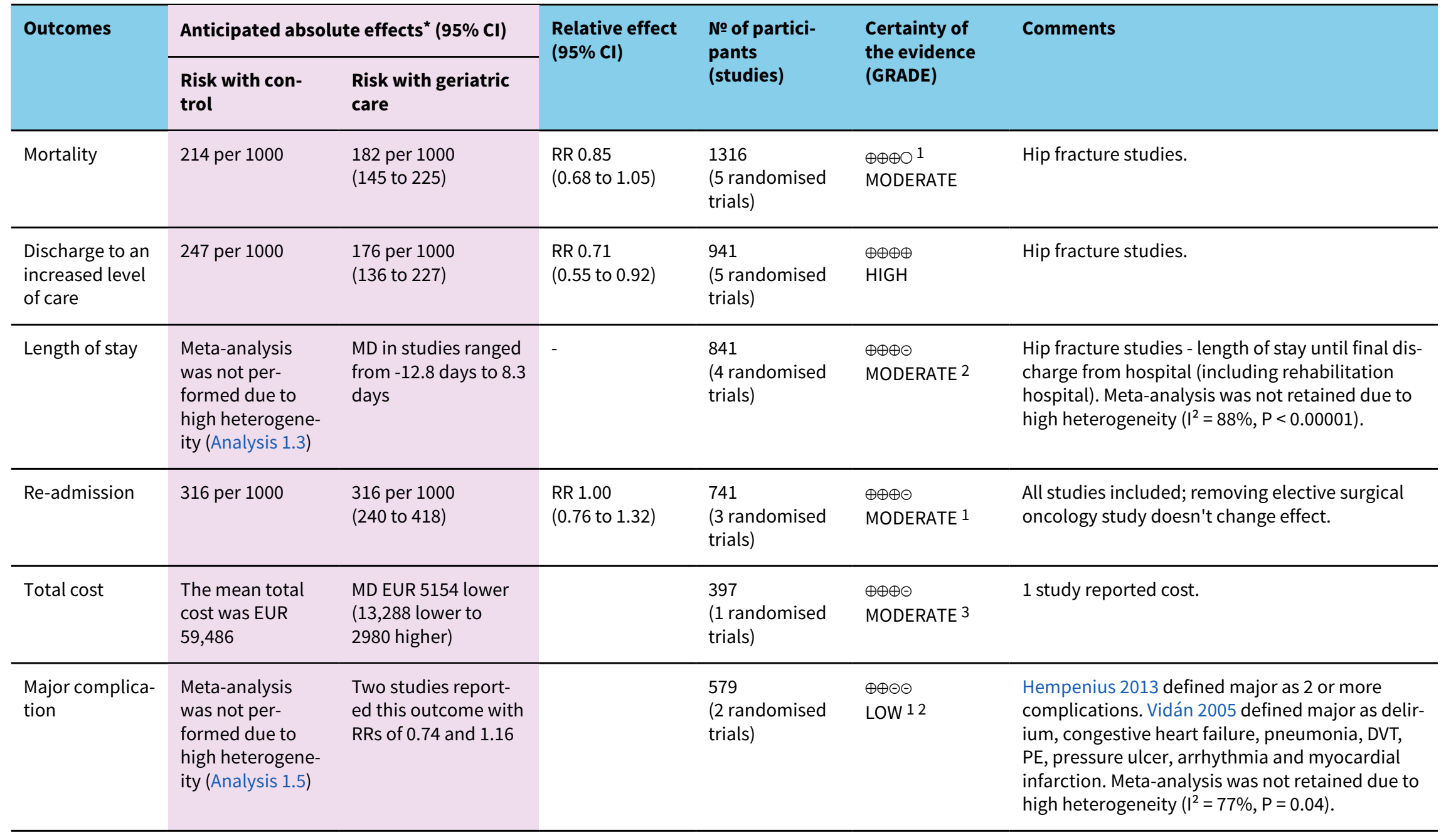




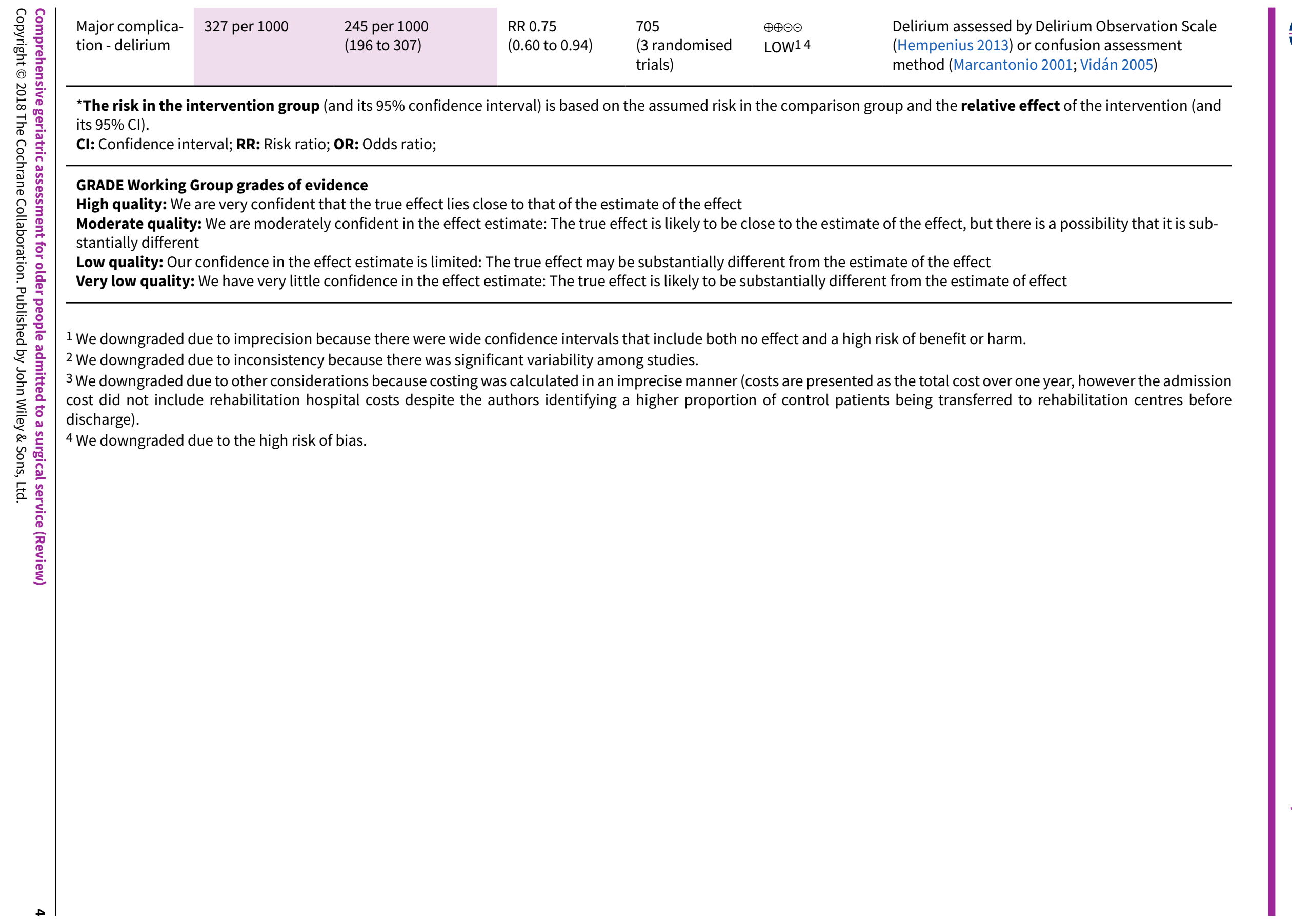




\section{B A C K G R O U N D}

This review assesses the effects of comprehensive geriatric assessment (CGA) on postoperative outcomes of older people admitted to hospital with a surgical problem.

\section{Description of the condition}

As the world's population ages, the demand for surgery among older people is increasing (Etzioni 2003). It is estimated that over half of all surgical operations are performed on people aged over 65 years (Geriatric Review Syllabus 2006). Compared to their younger counterparts, older people experience higher rates of postoperative complications, have a longer length of stay in hospital, and are more likely to require institutionalization after discharge (Lidsky 2012; Turrentine 2006). The increased costs and health resource use associated with older surgical patients place an additional strain on the healthcare system, highlighting the need for evidence-based interventions that can improve the outcomes of this patient population (Etzioni 2011).

\section{Description of the intervention}

CGA is a "multidisciplinary diagnostic process intended to determine a frail older person's medical, psychosocial, and functional capabilities and limitations in order to develop an overall plan for treatment and long-term follow-up" (Rubenstein 1991). CGA is not any one intervention in isolation, but rather a coordinated, multidisciplinary collaboration. This has already been successfully demonstrated on medical and orthogeriatric units (Ellis 2017; Frondini 2010; Prestmo 2015). Aspects of CGA are organized into three categories (medical, psychosocial, and functional) and may include a combination of the following factors (Rubenstein 1989).

\section{Medical}

- Primary diagnosis resulting in admission.

- Geriatrician following every eligible patient during their admission.

- Minimising the use of medications prone to causing delirium and adjusting dosing for geriatric syndromes.

- Comprehensive medication review by pharmacist.

Psychosocial

- Environmental cues to orient patient.

- Regular comfort rounds by nursing staff.

- Early discharge planning to anticipate and manage potential challenges.

Functional

- Fall risk assessment and mitigation.

- Physiotherapist intervention to prevent neuromuscular deconditioning.

- Occupational therapist to identify and manage barriers to independence.

- Physical environment modifications to reduce confusion, falls, delirium.

These interventions are conducted within a multidisciplinary collaboration to develop a unified plan of care for older people and were compared with usual care in a standard inpatient ward. CGA can be delivered at any point in a patient's care for elective surgical interventions and can be delivered postoperatively for emergency procedures. It is unclear if geriatric interventions before and after surgery are equally effective or if the interventions produce different effects in elective versus emergency surgery.

\section{How the intervention might work}

Older surgical patients have complex healthcare needs: frailty, multi-morbidity, and polypharmacy are common in this patient population (Bettelli 2011). However, most hospitals are structured to care for patients with a single, acute illness and are often illequipped to meet the needs of older people, leading to poor surgical outcomes. By performing a CGA, healthcare providers can identify and optimize medical and social issues associated with surgical complications before they have a negative impact on the health of the patient, which could improve outcomes.

\section{Why it is important to do this review}

Previous studies, notably a recent Cochrane Review that examined the effect of CGA on medical patient outcomes (Ellis 2017), have reported that if older people receive CGA on admission to hospital they are more likely to be alive and in their own homes at followup. However, most studies have focused on people admitted to hospital with general internal medicine issues, and to date there have not been any systematic reviews of CGA interventions focusing on surgical patients. There has also been no attempt to evaluate the role of timing of CGA and surgery on the effectiveness of the intervention.

\section{O B JECTIVES}

To assess the effectiveness of CGA interventions compared to standard care on the postoperative outcomes of older people admitted to hospital for surgical care.

\section{METHODS}

\section{Criteria for considering studies for this review \\ Types of studies}

We included randomised trials of postoperative participants. These could be from any surgical specialty, including emergency and elective surgery. The intervention groups received comprehensive geriatric assessment (CGA), compared to a control group receiving standard care. To reduce the likelihood of publication bias, we did not limit articles to the English language. We screened studies found in trial databases and the grey literature for eligibility.

\section{Types of participants}

The focus of this review was people aged 65 years or over in hospital under the care of an inpatient surgical ward. Although there is not a standard numerical criterion to define old age, 65 years is widely accepted as the chronological age to be considered an older person.

People admitted to hospital for elective or emergency surgery, or for an acute medical condition or injury requiring close observation and expectant management by a surgical team, were eligible for inclusion in the analysis. 
Studies containing a subset of surgical patients aged over 65 years were eligible for inclusion; we included study data pertaining to our population of interest in the meta-analysis

\section{Types of interventions}

We included studies in which a geriatrician, internist, geriatric nurse or another physician trained in geriatric assessment performed a multi-component geriatric assessment in hospital. Studies included participants receiving the intervention compared with participants receiving standard postoperative care. The CGA had to be performed by a clinician trained in geriatric assessment. CGA is typically performed as part of a mobile, multidisciplinary team consulted to provide patient management recommendations, or as part of a specialized ward dedicated to providing multidisciplinary care to geriatric surgical patients. The CGA intervention may be carried out pre-operatively, postoperatively, or throughout the patient's stay in hospital.

We excluded studies in which CGA was used exclusively as a tool to predict adverse postoperative events. We also excluded studies examining one aspect of the CGA instead of employing a multidimensional assessment, and we also excluded cross-over studies. We excluded enhanced recovery after surgery programmes because CGA is not a routine component of these programmes. Studies that did not report any of our predefined outcomes were also excluded.

\section{Types of outcome measures}

\section{Primary outcomes}

The primary outcomes were mortality and discharge to an increased level of care.

We measured mortality to the end of follow-up after treatment. We measured discharge to an increased level of care reported as participants being discharged to a setting where they would receive an increased level of care such as an assisted-living or long-term care facility, as opposed to returning to their pre-admission place of residence.

\section{Secondary outcomes}

Secondary outcomes included length of stay, re-admission rate, total cost and postoperative complications.

We measured length of stay as a continuous outcome reported as the number of days spent in hospital after surgery. Re-admission was measured as a dichotomous outcome representing the number of participants who were re-admitted in a given time period. Cost was recorded in euros (EUR) for 2016 after converting using Purchasing Power Parity (PPP) and the Gross Domestic Product (GDP) inflator as recommended by the Cochrane Handbook for Systematic Reviews of Interventions (Higgins 2011), but was not combined due to cross-jurisdictional differences in cost reporting and variation in data sources.

Postoperative complications included any of the following events in hospital after surgery: intensive care unit admission, vascular complications (e.g. myocardial infarction, stroke, deep venous thrombosis, and pulmonary embolism), serious infection, and delirium. For studies that did not report major complication categories, we recorded complication frequency by organ system (e.g. cardiovascular, respiratory, gastrointestinal, neurologic, etc.)
We reported all complications as a dichotomous outcomes. Complications not prone to detection bias, such as stroke and myocardial infarction, and those detected in studies with appropriate blinding of complication assessment, were more strongly weighted in the discussion. Delirium is particularly prone to detection bias due to the CGA intervention being more likely to detect delirium; we assessed how each study controlled for this aspect.

\section{Search methods for identification of studies}

\section{Electronic searches}

We used a sensitive search strategy to retrieve studies from electronic databases. We searched the following databases, with publication dates ranging from inception to 13 January 2017.

- Cochrane Central Register of Controlled Trials (CENTRAL; 2017, Issue 1), including the Cochrane Effective Practice and Organisation of Care (EPOC) Group Specialized Register, part of the Cochrane Library (www.cochranelibrary.com);

- MEDLINE In-Process \& Other Non-Indexed Citations, OvidSP (1946 to 13 January 2017);

- Embase, OvidSP (1974 to 13 January 2017);

- PsycINFO, OvidSP (1987 to 13 January 2017); and

- CINAHL (Cumulative Index to Nursing and Allied Health Literature), EBSCO (1980 to 13 January 2017).

The search terms combined Medical Subject Headings (MeSH) and free text words as shown in the search strategies in Appendix 1. We placed no restrictions on language, publication type, or publication year.

\section{Searching other resources}

We conducted a grey literature search to identify non-indexed studies not appearing in the databases listed above. Sources included:

- World Health Organization International Clinical Trials Registry Platform (WHO ICTRP) (www.who.int/ictrp/en/); and

- USA National Institutes of Health Ongoing Trials Register ClinicalTrials.gov (clinicaltrials.gov).

We used Science Citation Index to search the cited and citing articles of included studies.

\section{Data collection and analysis}

\section{Selection of studies}

Two review authors (GE and QD) screened titles and abstracts to identify potentially eligible articles for full-text review. We assessed potential eligibility based on design, participants, intervention, and outcomes as described, and excluded studies that did not meet the inclusion criteria at this stage. Two review authors (GE and AT or SC) independently carried out full-text review. We resolved conflicts between review authors at all stages of article screening and data extraction by discussion and consensus. We reported the number of excluded studies and the reason for exclusion as per Section 7.2.5 of the Cochrane Handbook (Higgins 2011). 


\section{Data extraction and management}

Two review authors (GE and AT or SC) independently extracted data onto web-based electronic data collection forms (Covidence), resolving disagreements between review authors by discussion and consensus. Data were exported to Review Manager 5 for analysis (Review Manager 2014).

During data extraction, we took note of the study source, eligibility, methods, participants, interventions, outcomes of interest, results, and other information as defined in Table 7.3.a of the Cochrane Handbook, in Higgins 2011, and the EPOC good-practice data extraction form (EPOC 2017a). All costs were reported in Euros.

\section{Assessment of risk of bias in included studies}

Two independent review authors used Cochrane's 'Risk of bias' tool (Higgins 2011) modified based on the EPOC guidance for risk of bias criteria (EPOC 2017b) to assess each study. Each study was evaluated based on the following criteria: low risk, high risk, or uncertain risk.

1. Random sequence generation - was the allocation sequence adequately generated?

2. Allocation concealment - was allocation concealment adequate?

3. Baseline demographics between groups - were baseline outcomes measured before the intervention and were they similar between groups?

4. Incomplete data - were loss to follow-up or dropouts low enough to limit risk of bias?

5. Blinding of participants and personnel - were participants and personnel blind to the intervention?

6. Blinding of outcome assessment - were outcome assessors blind to the intervention?

7. Protection from cross-contamination - were there safeguards to cross-contamination of the control group?

8. Selective reporting - were all outcomes in the methods reported in the results?

9. Other risks of bias - were any additional risks noted during bias assessment?

\section{Measures of treatment effect}

We reported dichotomous outcome data, such as the effect of CGA on patient mortality and discharge to an increased level of care, as risk ratios with $95 \%$ confidence intervals. We reported continuous outcome data such as the effect of CGA on length of stay using the mean difference between the CGA intervention and standard care with a $95 \%$ confidence interval. For all continuous-variable outcomes, we reported the mean and standard deviations or standard error of the outcome measurements in each intervention group, as well as the number of participants on which the outcome was measured. Due to the differences in delivery of CGA between studies we elected to use the random effects model for metaanalysis. We expected to find both study-to-study variability and within study variability resulting in differing true effects between studies. We used the fixed-effect model as a form of sensitivity analysis.

\section{Unit of analysis issues}

We performed analyses at the participant level to avoid unit of analysis errors. If we had identified cluster randomised trials, we would have used a ratio estimator approach to reduce the size of each cluster trial to its effective sample size (Rao 1992), which is its original sample size divided by design effect. The design effect is 1 $+(M-1)$ ICC, where M is the average cluster size and ICC is the intracluster correlation coefficient. For dichotomous data, the number of participants and the number of events would have been divided by the design effect. For continuous data, the sample size would have been divided by the design effect. Missing ICCS would have been selected from other cluster randomised trials included in the review or obtained from similar external studies. We would have conducted sensitivity analyses to investigate whether removing clustered trials affects the conclusions.

If the results of a study could not be adjusted for the unit of analysis error, we would have excluded it from the pooled analysis. We assessed length of stay based on time since admission to discharge and end of follow-up as predefined outcome measurement points but were unable to pool it due to high heterogeneity.

\section{Dealing with missing data}

Where feasible, we attempted to obtain missing data from study authors. We investigated attrition rates (e.g. dropouts, losses to follow-up, and withdrawals), and critically appraised issues of missing data and imputation methods (e.g. last observation carried forward). Where standard deviations for outcomes were not reported, we imputed these values by assuming the standard deviation of the missing outcome to be the average of the standard deviations from those studies where this information was reported. We investigated the impact of imputation on meta-analyses by means of sensitivity analysis.

\section{Assessment of heterogeneity}

Where we considered studies similar enough based on population, study design, and setting to allow pooling of data using metaanalysis, we assessed the degree of heterogeneity by visual inspection of forest plots and by examining the $\mathrm{Chi}^{2}$ test for heterogeneity. We quantified heterogeneity between studies using the $\mathrm{I}^{2}$ test. An $\mathrm{I}^{2}$ of less than $40 \%$ was considered unimportant; $40 \%$ to $60 \%$ may indicate moderate heterogeneity; $60 \%$ to $75 \%$ may indicate substantial heterogeneity; and $75 \%$ to $100 \%$ indicates considerable heterogeneity. Where we detected substantial clinical, methodological, or statistical heterogeneity across included studies, we did not retain the pooled results from meta-analysis but instead used a narrative approach to data synthesis.

\section{Assessment of reporting biases}

We assessed publication bias by searching trial registries and searching for grey literature through citation chaining. For studies published after 1 July 2005, we noted lack of registration of the trial protocol with the WHO ICTRP in the 'Risk of bias' table. We also noted selective reporting of predefined outcomes.

\section{Data synthesis}

We compared random-effects and fixed-effect models to assess if smaller studies affect the results. Given the complex and multidimensional nature of CGA, variation is expected in measured 
outcomes due to sampling error and differing patterns of implementation of CGA. If there was a difference between fixedeffect and random-effects models, we assessed the impact of small studies on the estimate of effect before deciding which model to use.

\section{Summary of findings}

We summarized the findings of the main intervention comparison for the most important outcomes included in the review. We graded our primary outcomes (mortality and discharge to an increased level of care) and secondary outcomes (length of stay, re-admission rate, cost and postoperative complication rates) as a means to assess the certainty of the evidence. Two review authors (GE and AT) independently assessed the certainty of the evidence (high, moderate, low, and very low) using the five GRADE considerations (study limitations, consistency of effect, imprecision, indirectness, and publication bias). We used the methods and recommendations described in Section 8.5 and Chapter 12 of the Cochrane Handbook (Higgins 2011), the EPOC worksheets (EPOC 2017c), and the GRADE Working Group guidelines (Guyatt 2008), and the GRADEpro software was used to grade each outcome (GRADEpro GDT 2015). We resolved disagreements on certainty ratings by discussion. Justification for decisions to either downgrade or upgrade the ratings are available as footnotes in Summary of findings for the main comparison and the full GRADE evidence profile is available as Appendix 2.

\section{Subgroup analysis and investigation of heterogeneity}

We conducted subgroup analysis for the a priori defined variables listed below.

1. Orthopedic versus other surgical specialties.

2. CGA timing - is the CGA conducted pre-operatively, postoperatively, or throughout an admission?

3. Emergency versus elective surgery.

We analyzed these subgroups at discharge and at end of followup. We determined if the subgroups differ by inspecting the overlap of confidence intervals and testing for subgroup differences using Review Manager 5 (Review Manager 2014).
Timing of the CGA in relation to surgery could affect patient outcomes because the potential benefits of CGA intervention could arise from optimizing patient medical and social issues before surgery; by providing a better level of care following surgery; or both pre- and postoperative intervention may be necessary to see benefits. Most studies of CGA in surgical patients have been performed in orthopedic trauma (hip fracture); the effect of CGA may play an important role in recuperation from hip surgery but not in other surgical interventions or populations. Finally, elective versus emergency surgery can give rise to different risk profiles. Determining if there is a benefit in one population versus another is important.

\section{Sensitivity analysis}

We were unable to perform sensitivity analysis to explore changes in effect size after removing studies with a high risk of bias due to the small number of studies identified. We compared the use of a fixed-effect and random-effects models.

\section{RES U LT S}

\section{Description of studies}

\section{Results of the search}

A literature search conducted by a trained librarian on 13 January 2017 identified 14,874 citations for title screening. The citations were from CENTRAL (666 citations), MEDLINE (5663 citations), Embase (7823 citations), PsycINFO (446 citations) and CINAHL (3229 citations). We identified three additional citations through reference screening. During title and abstract screening we identified and removed 655 additional duplicated citations leaving 14,222 records to screen; 363 citations underwent full text screening (Figure 1). We included eight randomised trials (Hempenius 2013; Hempsall 1990; Kennie 1988; Marcantonio 2001; Naglie 2002; Prestmo 2015; Stenvall 2007; Vidán 2005). All hip fracture studies excluded pathologic fractures and participants who were entirely dependent on others for care before their fracture. 
Figure 1. Study flow diagram.

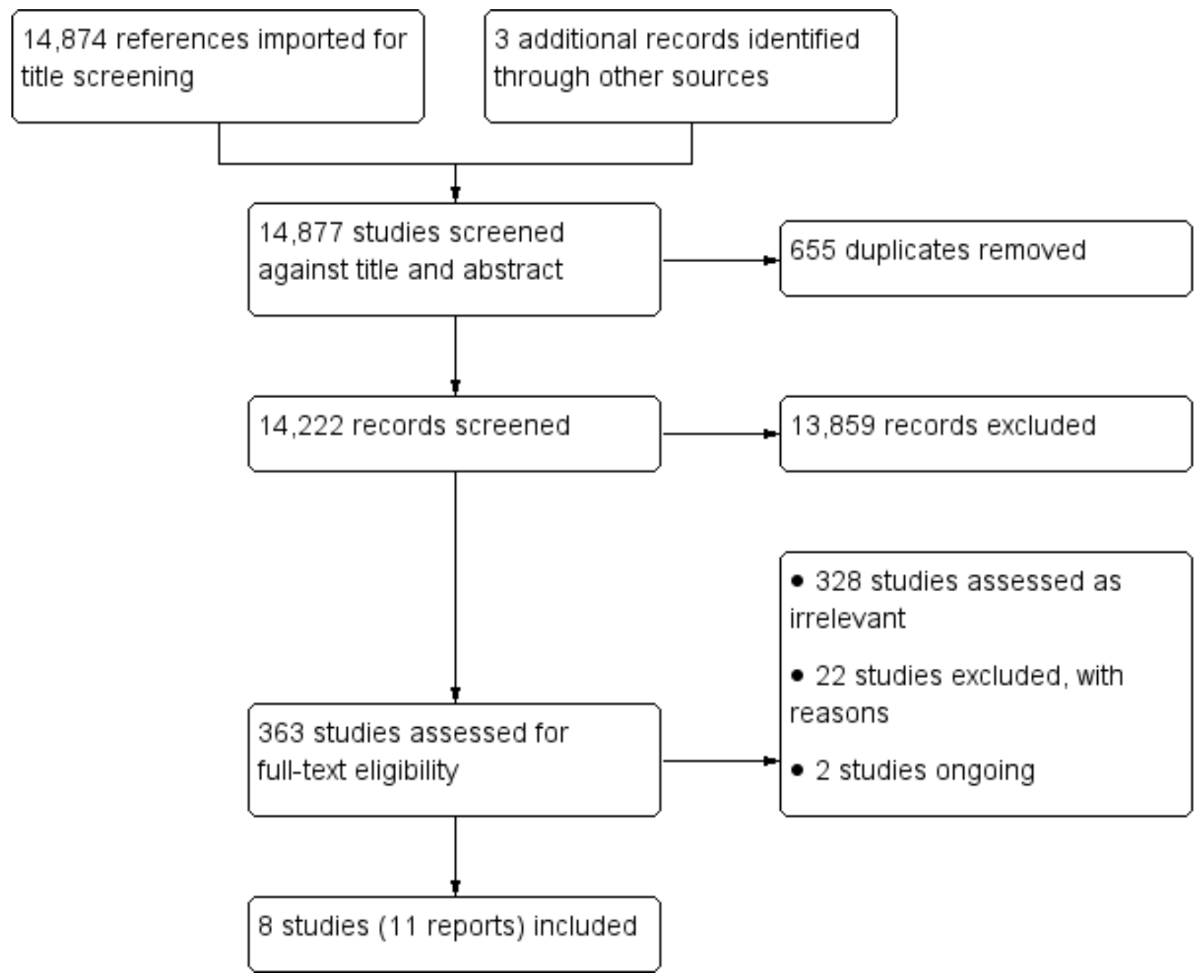

\section{Included studies}

We included eight randomised trials with a total of 1843 participants enrolled. Three studies enrolled participants aged 70 years and over (Naglie 2002; Prestmo 2015; Stenvall 2007) while the remaining five enrolled participants who were aged 65 years and over (Hempenius 2013; Hempsall 1990; Kennie 1988; Marcantonio 2001; Vidán 2005). All but one study (Hempenius 2013) were conducted at a single site. Seven studies recruited participants with hip fracture (Hempsall 1990; Kennie 1988; Marcantonio 2001; Naglie 2002; Prestmo 2015; Stenvall 2007; Vidán 2005) while the remaining study recruited participants admitted for elective surgical oncology (Hempenius 2013). Six studies randomised participants to comprehensive geriatric assessment (CGA) versus standard care pre-operatively (Hempenius 2013; Marcantonio 2001; Naglie 2002; Prestmo 2015; Stenvall 2007; Vidán 2005) and two studies randomised postoperatively (Hempsall 1990; Kennie 1988). CGA and geriatric care were delivered during acute postoperative recovery in six studies (Hempenius 2016; Marcantonio 2001; Naglie 2002; Prestmo 2015; Stenvall 2007; Vidán 2005) and in a rehabilitation setting in two trials (Hempsall 1990; Kennie 1988). Additionally, two studies included a pre-operative assessment (Hempenius 2013; Prestmo 2015). All studies were published in the
English language. There two ongoing studies (Baroni 2016, Brugel 2014) and no studies are awaiting classification.

Hempenius 2013 enrolled participants undergoing elective surgery for a solid tumour. The intervention included a pre-operative CGA, development of a individualized care plan and daily visits postoperatively by a geriatric liaison nurse who provided advice on any problems encountered. Funding was from the Netherlands Organization for Health Research and Development.

Hempsall 1990 enrolled participants presenting with neck of femur fracture, who were randomised based on their geographic setting to geriatric assessment and rehabilitation at a dedicated geriatric facility or standard orthopedic rehabilitation. The funding source was not disclosed.

Kennie 1988 enrolled participants presenting with a hip fracture, who were randomised to a dedicated orthogeriatric rehabilitation ward at a separate hospital or to remain on the orthopedic ward for rehabilitation. Funding was provided by the Forth Valley Health Board.

Marcantonio 2001 also enrolled participants with hip fractures, who were randomised to usual surgical care or proactive geriatric 
consultation pre-operatively or within 24 hours of surgery. The consultant geriatrician provided daily assessments and advice to the surgical team. Funding was provided by the Older Americans Independence Center, the Charles Farnsworth Trust, the National Institute on Aging and the Medical Foundation: Charles A King Trust.

Participants in Naglie 2002 also had hip fracture and were randomised to postoperative interdisciplinary care or usual surgical care. Interdisciplinary care consisted of routine assessment by a geriatrician, physiotherapy, occupational therapy, social worker and clinical nurse specialists. Funding was provided by Canadian research and governmental entities.

The participants in Prestmo 2015, also with hip fracture, were randomised to comprehensive geriatric care versus usual surgical care. Geriatric care consisted of primary pre- and postoperative care from a geriatrician on a dedicated geriatric ward without regular input from orthopedic surgeons. The study was funded by Norwegian research, educational, and governmental entities.

Stenvall 2007 enrolled and randomised participants with hip fracture, who then received care in either a geriatric or an orthopedic ward. The geriatric ward provided comprehensive geriatric assessments and rehabilitation that included early mobilization. Funding was provided by Swedish research, educational, and governmental entities.

Participants in Vidán 2005 also had hip fracture, and were randomised to either usual care or to postoperative care from a dedicated geriatric team that included a geriatrician, a rehabilitation specialist and a geriatric social worker. Funding was provided by the Spanish governmental entities.

\section{Intervention}

All identified studies used CGA to assess participants in the experimental arm, defined as a biopsychosocial approach to care for the elderly that incorporates a multidisciplinary team to address patients' medical illness, physical decline and social factors that slow recovery.

The model for delivery of CGA was quite varied; the physician responsible for care was a surgeon in three studies (Hempenius 2013; Marcantonio 2001; Naglie 2002), a geriatrician in three (Prestmo 2015; Stenvall 2007; Vidán 2005), a general practitioner in one (Kennie 1988) and was unclear in one study (Hempsall 1990). Trials with a non-orthopedic primary physician all had consultation from the orthopedic surgeon available as needed.

The interventions varied among studies, but all included a comprehensive geriatric assessment. One study developed a geriatric treatment plan pre-operatively that was monitored by a geriatric nurse postoperatively; postoperative consultation with a geriatrician was performed as needed (Hempenius 2013). Three studies performed geriatric rounds as a consultation service, two conducted rounds on a daily basis (Marcantonio 2001; Naglie 2002) and one conducted rounds twice a week (Kennie 1988). One study included only female participants (Kennie 1988).

\section{Outcomes}

Our primary outcomes were mortality and discharge to an increased level of care. Six studies reported mortality (Hempenius 2013; Hempsall 1990; Naglie 2002; Prestmo 2015; Stenvall 2007;
Vidán 2005) and six studies reported discharge to an increased level of care (Hempenius 2013; Kennie 1988; Naglie 2002; Prestmo 2015; Stenvall 2007; Vidán 2005).

Our secondary outcomes were length of stay, re-admission, cost and complications. Five studies reported length of stay (Hempsall 1990; Naglie 2002; Prestmo 2015; Stenvall 2007; Vidán 2005), three studies reported re-admission (Hempenius 2013; Prestmo 2015; Stenvall 2007), one study reported cost (Prestmo 2015) and three studies reported complications (Hempenius 2013; Marcantonio 2001; Vidán 2005). Complications were presented in different manners among studies, limiting the ability to pool results.

\section{Setting}

The eight included trials were conducted in seven countries. Two studies were conducted in North America (USA and Canada) (Marcantonio 2001; Naglie 2002) and six studies were conducted in Europe (Spain, UK, Netherlands, Norway and Sweden) (Hempenius 2013; Hempsall 1990; Kennie 1988; Prestmo 2015; Stenvall 2007; Vidán 2005).

\section{Excluded studies}

We assessed 331 studies as irrelevant and excluded 22 studies with reasons, most commonly due to having the wrong patient population and ineligible outcomes. (See Figure 1 and Characteristics of excluded studies).

\section{Ongoing studies}

Two studies are ongoing (Baroni 2016; Brugel 2014).

\section{Risk of bias in included studies}

\section{Allocation}

Six studies used adequate methods to generate random sequencing (Hempenius 2013; Kennie 1988; Marcantonio 2001; Naglie 2002; Prestmo 2015; Stenvall 2007) and five studies appropriately concealed allocation (Naglie 2002; Hempenius 2013; Marcantonio 2001; Prestmo 2015; Stenvall 2007). One study was unclear about randomisation technique (Vidán 2005), one did not adequately perform allocation and did not conceal allocation (Hempsall 1990) and two studies did not adequately describe allocation concealment methods to permit judgement (Kennie 1988; Vidán 2005).

\section{Blinding}

Blinding of participants was not possible because of the nature of the intervention; many of the studies included in our review measured outcomes, such as mortality or length of stay, that are objective and less prone to performance or detection bias. Consequently, where we felt the outcome being assessed was not prone to bias and the study design was adequately described, we assessed the risk of bias for blinding of participants as low. Overall, five studies were deemed to have a low risk of performance bias (Hempsall 1990; Kennie 1988; Marcantonio 2001; Naglie 2002; Stenvall 2007) and four studies had a low risk of detection bias (Hempsall 1990; Marcantonio 2001; Naglie 2002; Stenvall 2007). Two studies did not adequately explain how they blinded participants (Prestmo 2015; Vidán 2005) and four did not explain the how they blinded their outcome assessors (Hempenius 2013; Kennie 1988; Prestmo 2015; Vidán 2005). One study had a high risk of performance bias (Hempenius 2013); the primary outcome 
was delirium and we cannot be sure that lack of blinding did not influence the results.

\section{Incomplete outcome data}

Seven of eight studies reported low attrition rates (Hempenius 2013; Hempsall 1990; Kennie 1988; Marcantonio 2001; Naglie 2002; Prestmo 2015; Stenvall 2007) while one study provided insufficient data to assess attrition (Vidán 2005).

\section{Selective reporting}

Seven studies reported all outcomes that were expected and were therefore judged to be at low risk of reporting bias (Hempenius 2013; Kennie 1988; Marcantonio 2001; Naglie 2002; Prestmo 2015; Stenvall 2007; Vidán 2005). One study did not report all expected outcomes and consequently was deemed to have a high risk of reporting bias (Hempsall 1990). Two studies were published during or after 2005 and did not register their trial. Vidán 2005 collected data in 1997 and Stenvall 2007 collected data between

\section{Figure 2. Risk of bias graph: review authors' judgements about each risk of bias item presented as percentages across all included studies.}

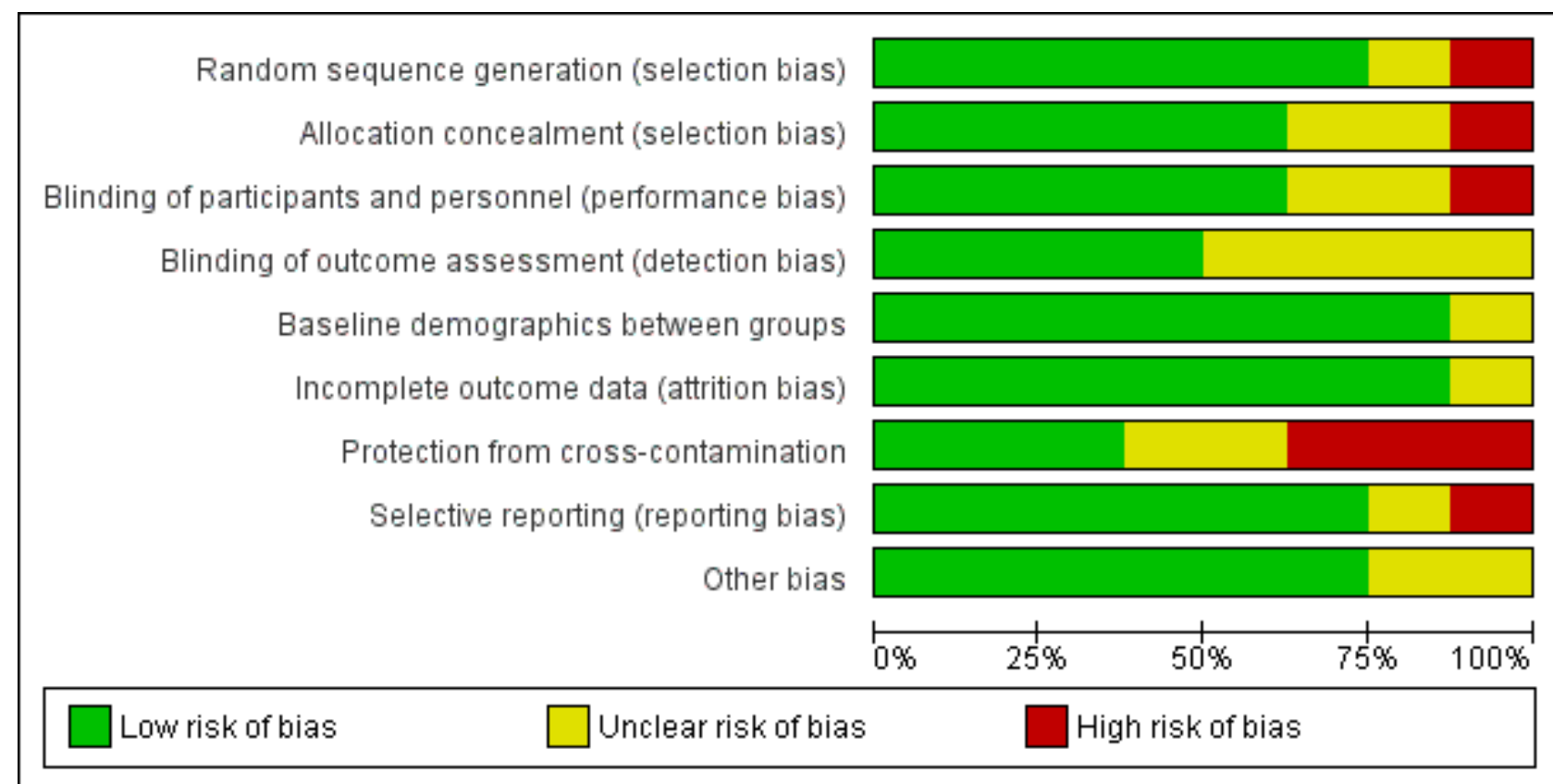


Figure 3. Risk of bias summary: review authors' judgements about each risk of bias item for each included study.

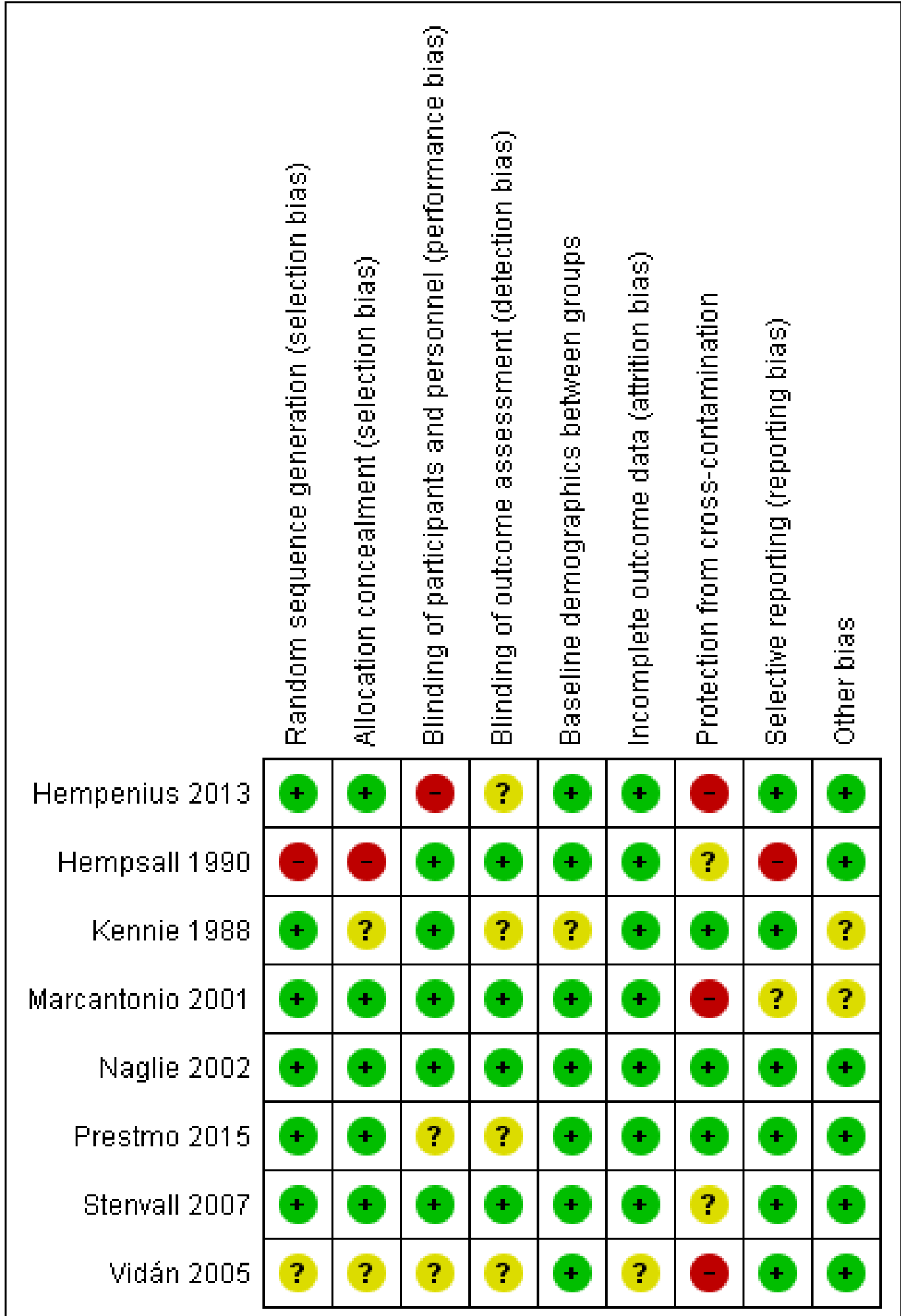

\section{Effects of interventions}

See: Summary of findings for the main comparison Comprehensive geriatric assessment for older people admitted to a surgical service
See the Summary of findings for the main comparison for summarized results and certainty of evidence.

We identified eight trials, representing 1843 participants. Seven trials, with 1583 participants, were in people with hip fracture while 
one study (Hempenius 2013), with 260 patients, was in elective surgical oncology participants. Pooled analysis conducted both with and without the elective surgical oncology trial are presented.

\section{Comprehensive geriatric assessment versus usual care for older people admitted to a surgical service}

\section{Primary outcomes}

\section{Mortality}

Five orthopedic trials with 1316 participants reported mortality outcomes. Using a random-effects model, CGA probably reduces mortality in older people with hip fracture (risk ratio (RR) 0.85 , $95 \%$ confidence interval $(\mathrm{Cl}) 0.68$ to $1.05,5$ trials, 1316 participants, Analysis 1.1, moderate-certainty evidence). No heterogeneity was identified between the trials reporting mortality $\left(\mathrm{I}^{2}=0 \%\right)$. Using a fixed-effect model did not change the outcome of the analysis. When the elective surgical oncology trial was included in the analysis, heterogeneity increased $\left(I^{2}=26 \%\right)$ and the risk ratio moved closer to 1 (RR $0.90,95 \% \mathrm{Cl} 0.73$ to $1.10,6$ trials, 1576 participants).

\section{Discharge to an increased level of care}

Five orthopedic trials reported discharge to an increased level of care from hospital for 941 participants. Discharge to an increased level of care was defined as participants being discharged to a higher level of care than they required before admission (e.g. discharged to an assisted living residence instead of returning to independent living). Using a random-effects model, the intervention reduces discharge to an increased level of care (RR $0.71,95 \% \mathrm{Cl} 0.55$ to $0.92,5$ trials, 941 participants, Analysis 1.2 , high-certainty evidence). There was no heterogeneity between the orthopedic studies $\left(I^{2}=0 \%\right)$. Using a fixed-effect model did not change the results. One study reported discharge from hospital to a "nursing home [or] rehab hospital" (Marcantonio 2001). They did not distinguish between nursing home admission and rehabilitation hospital stay and did not report discharge destination following rehabilitation. Consequently, this study was excluded from the assessment. Inclusion of the elective surgical oncology trial profoundly increased heterogeneity $\left(I^{2}=61 \%\right)$ and resulted in CGA having little or no effect on discharge destination (RR $0.86,95 \% \mathrm{Cl} 0.69$ to $1.07,6$ trials, 1164 participants).

\section{Secondary outcomes}

\section{Length of stay}

Five trials reported length of stay. There was considerable heterogeneity among studies when using either fixed-effect $\left(I^{2}\right.$ $=88 \%)$ or random-effects models $\left(I^{2}=88 \%\right)$. Due to the high heterogeneity, we examined the outcomes individually. All studies that reported length of stay recruited participants with hip fracture. The mean difference between participants allocated to the intervention and the control groups ranged between -12.8 and 8.3 days (Analysis 1.3). Three studies reported a reduction in length of stay (Hempsall 1990; Stenvall 2007; Vidán 2005) while two reported an increased length of stay (Naglie 2002; Prestmo 2015).

Prestmo 2015 reported the length of time participants spent in the acute hospital; they reported fewer participants in the CGA arm required admission to a rehabilitation hospital but did not report a cumulative length of stay including rehabilitation.
Naglie 2002 reported that fewer participants in the CGA arm were transferred from the acute hospital to a nursing home but more were transferred to a rehabilitation hospital. Overall, at six months follow-up, results were similar for the mean number of "days spent in institutions (including acute hospitals, rehabilitation hospitals and nursing homes) over 6 months".

Four of the five studies reporting length of stay found decreased length of stay or decreased transfer to a rehabilitation hospital while one found little or no difference in "institution" use (mean 111 versus 110 days, $P=0.84$ ) at six months follow-up. The intervention probably leads to slightly reduced length of stay (4 trials, 841 participants, moderate-certainty evidence).

\section{Re-admission}

Re-admission was reported by three trials: two orthopedic and one surgical oncology. Pooled results were limited by the small number of studies reporting re-admission. The intervention probably makes little or no difference in re-admission rates (RR 1.00, 95\% $\mathrm{Cl} 0.76$ to 1.32 , 3 studies, 741 participants, Analysis 1.4, moderatecertainty evidence). There was moderate heterogeneity $\left(1^{2}=37 \%\right)$ among the three studies. Removing the elective surgical oncology study (Hempenius 2013) increased heterogeneity $\left(I^{2}=53 \%\right)$ but did not change the pooled result.

\section{Cost}

Cost was reported by one study (Prestmo 2015). The mean total cost at one year follow-up was EUR 59,486 in the control arm and EUR 54,332 in the CGA arm (MD EUR 5154, 95\% Cl-13,288 to 2980, 1 trial, 397 participants, moderate-certainty evidence). Prestmo 2015 found that the incremental cost effectiveness ratio was EUR 71,751, suggesting CGA probably slightly reduced total cost (1 trial, 397 participants, moderate-certainty evidence).

\section{Postoperative complications}

Three studies reported postoperative complications, but we were unable to pool results due to the manner in which they were reported. Two studies, representing 579 participants, reported major complications (Hempenius 2013; Vidán 2005). There was considerable heterogeneity between the studies making pooled meta-analysis inappropriate. Hempenius 2013 defined a major complication as two or more pulmonary, neurologic (excluding delirium), cardiovascular or thromboembolic complications. Vidán 2005 defined major complications as delirium, congestive heart failure, pneumonia, deep venous thrombosis, pulmonary embolus, pressure ulcer, arrhythmia and myocardial infarction. Most significantly, Vidán 2005 included delirium as a major complication and Hempenius 2013 did not. CGA may make little or no difference for major postoperative complications ( 2 trials, 579 participants, low-certainty evidence).

Three studies reported delirium as an independent outcome (Hempenius 2013; Marcantonio 2001; Vidán 2005), representing 705 participants. Using a random-effects model, CGA may make litte or no difference for delirium (RR $0.75,95 \% \mathrm{Cl} 0.60$ to $0.94,3$ trials, 705 participants, Analysis 1.6, $\mathrm{I}^{2}=0 \%$, low-certainty evidence). Using a fixed-effect model did not change the results of pooled analysis.

\section{Sensitivity analysis by trial quality}

There were too few studies in the low risk of bias subgroups to permit sensitivity analysis by trial quality. 


\section{Subgroup analysis}

Analysis of orthopedic versus non-orthopedic results was conducted by removing the only non-orthopedic trial from pooled analysis. The results are reported above. The non-orthopedic trial was also the only elective trial identified by our search.

Subgroup analysis of trials where CGA was conducted postoperatively was performed by excluding studies where CGA was conducted before surgery. We assessed the primary outcomes after removing Hempenius 2013 and Prestmo 2015; CGA probably reduces mortality if it is performed after surgery (RR $0.87,95 \% \mathrm{Cl}$ 0.68 to $1.11,938$ participants, 4 studies, random-effects model, $\mathrm{I}^{2}=$ $0 \%$, moderate-certainty evidence) and probably reduces discharge to an increased level of care (RR $0.71,95 \% \mathrm{Cl} 0.49$ to $1.02,612$ participants, 4 studies, random-effects model, $\mathrm{I}^{2}=25 \%$, moderatecertainty evidence) although the confidence interval was slightly wider and crossed 1 .

We also assessed secondary outcomes. Length of stay was highly heterogeneous, three of five studies found decreased length of stay, one found increased length of stay but a lower transfer rate to rehabilitation hospitals and one did not find any difference at six month follow-up. The two studies reporting delirium rates after performing postoperative CGA (Marcantonio 2001; Vidán 2005) indicate that the intervention may make little or no difference to delirium (RR $0.75,95 \% \mathrm{Cl} 0.56$ to 1.01, 445 participants, 2 studies, $1^{2}=24 \%$, low-certainty evidence). After removing both studies that performed pre-operative assessment, one trial reported major complications (Vidán 2005), one study reported re-admission (Stenvall 2007) and no trials reported cost.

Meta-regression could not be performed due to the small number of included studies.

\section{DISCUSSION}

\section{Summary of main results}

We included eight randomised trials $(N=1843)$. Seven recruited participants who were recovering from a hip fracture (1583 participants) and one was in elective surgical oncology (260 participants). Pooled analysis of five studies of hip fracture in older people indicated that CGA probably reduces mortality (moderatecertainty evidence). The intervention reduced discharge to an increased level of care in older adults with hip fracture (highcertainty evidence).

Heterogeneity was considerable for length of stay, preventing data pooling. The intervention probably leads to slightly reduced length of stay (moderate-certainty evidence). CGA probably makes little or no difference to re-admission rates (moderate-certainty evidence). One study reported cost, bootstrap analysis suggests CGA probably slightly reduces total cost (moderate-certainty evidence). Major complications were highly heterogenous and were defined differently by the two studies reporting this outcome. CGA may make little or no difference for major postoperative complications and delirium (low-certainty evidence).

\section{Overall completeness and applicability of evidence}

All studies recruited surgical participants who were admitted to an acute care hospital in Western Europe or North America. We identified one high quality trial in non-orthopedic surgical populations (Baroni 2016) and two ongoing studies from nonorthopedic surgical older people that have not yet reported results (Baroni 2016; Brugel 2014).

All geriatric assessments were supervised by a geriatrician, however the physician responsible for care varied among studies. The responsible physician in the experimental arm was a geriatrician in four studies (Naglie 2002; Prestmo 2015; Stenvall 2007; VidÃjn 2005) and the surgeon in two (Hempenius 2013; Marcantonio 2001). Additionally, two studies did not perform CGA until the patient was ready for transfer to a rehabilitation ward (Hempsall 1990; Kennie 1988).

The total number of participants identified $(N=1843)$ is sufficiently large that we feel we can confirm effectiveness and safety for outcomes reported by most trials. Outcomes reported by a small number of trials included fewer participants and may not reliably represent the true safety and efficacy of the intervention. These outcomes include cost $(\mathrm{N}=397)$, complications $(\mathrm{N}=579)$ and readmission ( $N=516)$. The time of follow-up was also quite varied among studies; some participants were followed until discharge while others as long as one year. This aspect may limit the reliability of these results due to smaller numbers of participants in the pooled results.

We included two studies that did not perform geriatric assessment until the patient was ready for transfer to a rehabilitation ward (Hempsall 1990; Kennie 1988). Neither study reported postoperative complications or delirium. The participants in these studies were cared for by an orthopedic surgeon until they were transferred to a rehabilitation facility that provided specialized geriatric rehabilitation with CGA compared to usual orthopedic care. The physician primarily responsible for patients' care during rehabilitation was a general practitioner (Kennie 1988) or it was unclear who cared for them (Hempsall 1990). Hempsall 1990 reported three outcomes that are included in our review: mortality, length of stay and discharge to an increased level of care. Initial geriatric assessment was conducted between postoperative day 3 and 7 . The authors felt that events that occurred before postoperative day 8 could not have been affected by geriatric assessment; these events were censored from their results (Hempsall 1990). We feel that, given the censored data, these results are an accurate reflection of the effects of CGA (Hempsall 1990). Overall, the variability in implementation of CGA between studies introduces considerable heterogeneity and may limit comparability of the outcomes in the pooled results.

The potential to improve the care of older surgical patients is particularly relevant; aging populations are increasingly requiring surgical intervention and are prone to increased postoperative morbidity and mortality. The included studies support the implementation of CGA to decrease discharge to an increased level of care and complications for older people with hip fracture, but we cannot extend this recommendation for other surgical populations due to lack of high quality studies.

\section{Certainty of evidence}

We assessed certainty of evidence using the GRADE method and classified the certainty of evidence for our primary outcomes as moderate for mortality and high for discharge to an increased level of care for orthopedic studies. Individual studies had varied risk of bias, which partially depended on what outcome was being 
examined. Despite an overall elevated risk of bias in some of the included studies, the nature of our primary outcomes (mortality and discharge to an increased level of care) reduces the risk that these results are not representative of the overall population because these outcomes are not prone to detection or performance bias. The included studies had low dropout rates and most study authors responded when contacted. One study did not report mortality and the study authors were unable to provide data due to the time elapsed since the study was conducted. We noted no heterogeneity for mortality or discharge to an increased level of care when orthopedic studies were pooled; however, mortality was downgraded due to a wide confidence interval that crossed 1.

Secondary outcomes had lower certainty of evidence. Length of stay was downgraded due to high variability and heterogeneity, re-admission was downgraded due to imprecision and cost was downgraded due to indirectness; all were graded as moderatecertainty evidence. Evidence related to postoperative delirium was downgraded due to high risk of bias and imprecision. The evidence for the outcome of major complication was graded as low-certainty due to indirectness and imprecision of the measure.

\section{Potential biases in the review process}

We used the standard review methods of the Cochrane EPOC group to conduct this review. The use of an inclusive search strategy will have included all relevant studies.

\section{Agreements and disagreements with other studies or reviews}

Several other published reviews have examined the effect of CGA on outcomes. All identified reviews were for orthopedic trauma patients (hip fracture) and included both randomised trials and lower quality studies. Sabharwal 2015 identified five articles, comprising two prospective randomised and three retrospective cohort or observational trials, that all reported lower mortality in the CGA arm. Sabharwal 2015 identified multiple, predominantly retrospective, studies that identified reduced postoperative complications and reported that length of stay was lower with CGA in four of the five included studies. Three studies, one retrospective and two prospective randomised trials, identified improved functional outcomes in the intervention arms. Grigoryan 2014 , in a systematic review of 18 studies, reported that geriatric consultation services but not shared care reduced short- and longterm mortality, and that shared care but not geriatric consultations services reduced length of stay. Buecking 2013 included five trials, with high heterogeneity, and found little or no effect on length of stay and short- or long-term mortality. Deschodt 2013 performed a systematic review and meta-analysis of people receiving care on dedicated geriatric wards versus usual care. Deschodt 2013 included both medical $(n=9)$ and surgical $(n=3)$ studies. Deschodt 2013 reported no effect on functional status with CGA in 11 trials (including all 3 surgical trials), no effect on length of stay in 10 trials (including all 3 surgical trials) and no effect on re-admission in eight trials (including 2 surgical trials). Deschodt 2013 identified discordant results for mortality, which was reduced at six and eight months follow-up but not at one, three or 12 months followup (mortality was reported by all 3 surgical trials). Finally, Eamer $2017 \mathrm{~b}$, also reported a systematic review and meta-analysis of eight cost analysis or economic evaluation studies of CGA versus usual care. Seven of the eight studies were retrospective and of lower quality; however, all eight studies found improved outcomes at lower cost to the healthcare system with CGA.

Prestmo 2015 conducted a systematic review as part of their publication searching for orthogeriatric care models, but did not summarize results. Kammerlander 2010 performed a systematic literature review of enhanced orthopedic care for people with hip fracture and summarized findings classified by geriatric intervention type. Kammerlander 2010 performed a narrative analysis but did not pool data from the included studies. Several different models of care delivery including proactively consulted geriatrician (daily or less frequent consultations), geriatric ward postoperatively with orthopedic consultation and interdisciplinary care with integrated geriatric and orthopedic care teams were identified. Most studies, no matter the intervention type, did not identify any difference in mortality. There was wide variability in length of stay depending on the model used, but no clear reason was given to fully explain these differences. Complications were examined, but the high variability in how complications were defined made comparison between studies difficult (Kammerlander 2010).

No reviews identified adverse events related to the introduction of CGA into the model of care and most identified improvement in at least one outcome. Sabharwal 2015 and Grigoryan 2014 reported reduced mortality with CGA; Buecking 2013 did not find reduction in mortality, and Deschodt 2013 reported discordant results. Sabharwal 2015 reported decreased discharge to an increased level of care but Deschodt 2013 did not find a difference. No reviews reported cost. Only Sabharwal 2015 reported complications, which were decreased with CGA.

All identified reviews included lower-quality study designs, including retrospective chart reviews and historically-controlled trials. All reviews concluded that CGA showed benefits. However, Deschodt 2013 was unable to identify a clear added benefit from an integrated geriatric consultation service.

\section{AUTHORS' CONCLUSIONS}

\section{Implications for practice}

There is evidence that comprehensive geriatric assessment (CGA) probably decreases mortality and discharge to an increased level of care. One study that recruited participants recovering from a hip fracture reported a trend toward lower cost in the CGA arm, and following bootstrap analysis, CGA was found to be dominant to usual surgical care (CGA improved outcomes at lower cost). Overall, we found evidence that CGA improved some outcomes and did not worsen any of the outcomes examined in this review. Additionally, the improved outcomes may be accomplished with lower overall costs to the healthcare system compared to usual surgical care. CGA could be incorporated into the care of older adults presenting with hip fracture without the need for increased net investment in healthcare resources.

There is inadequate evidence to determine which CGA delivery method is most effective or how the timing of CGA (before or after surgery) affects the results or its effectiveness. There are too few studies in surgical patients to determine if CGA is effective in improving outcomes in people presenting with surgical complaints other than hip fracture. Only one high quality study considered a population other than hip fracture patients: the population studied 
was elective surgical oncology patients. This study did not identify any effect from the intervention. It is unclear if CGA was ineffective in this study because the intervention was in elective surgical patients or if CGA is not beneficial in surgical oncology.

\section{Implications for research}

At the date of the most recent literature search for this review (13 January 2017) the available evidence suggests comprehensive geriatric assessment is the dominant economic and clinical choice in hip fracture patients, but there is inadequate evidence to draw conclusions about whether CGA is effective in other surgical populations, what the most effective CGA delivery model is or whether CGA has different effectiveness in emergency versus elective surgical interventions. Large, high-quality randomised trials in people admitted for surgery other than hip fracture are needed to determine of CGA is effective in these populations. Trials to determine the effectiveness of CGA in elective surgical patients are also needed. Furthermore, trials are needed to determine which CGA delivery method is most effective and if the timing of CGA affects its effectiveness.

\section{ACK N O WLEDGEMENTS}

As part of the pre-publication editorial process, the protocol was commented on by Graham Ellis, Julia Worswick, Kristoffer Yungpeng Ding, Paul Miller, and Sasha Shepperd. We thank them for their valuable contribution to the protocol. We would like to thank Liz Dennett and Paul Miller for reviewing and providing excellent feedback on the search strategy.

The full review was commented on by Julia Worswick and Daniela Gonçalves Bradley before peer referee. Both provided critical appraisal and editorial assistance. External review was conducted by Lynn Shields, Andrea Schoenenberger, Sofia Massa, and Paul Miller. We are grateful for their thoughtful and thorough review and comments. Signe Flottorp and Sasha Shepperd provided editorial support.

Finally, we acknowledge the National Institute for Health Research, via Cochrane Infrastructure funding to the Effective Practice and Organisation of Care Group. The views and opinions expressed therein are those of the authors and do not necessarily reflect those of the Systematic Reviews Programme, National Institute for Health Research, National Health Service, or the Department of Health. 


\section{RE F E R E N C E S}

\section{References to studies included in this review}

Hempenius 2013 \{published data only\}

Hempenius L, Slaets JP, van Asselt D, de Bock TH, Wiggers T, van Leeuwen BL. Long term outcomes of a geriatric liaison intervention in frail elderly cancer patients. PloS One 2016;11(2):e0143364.

* Hempenius L, Slaets PJ, van Asselt D, de Bock GH, Wiggers T, Van Leeuwen BL. Outcomes of a geriatric liaison intervention to prevent the development of postoperative delirium in frail elderly cancer patients: Report on a multicentre, randomized, controlled trial. PloS One 2013;8(6):e64834. [DOI: 10.1371/ journal.pone.0064834]

\section{Hempsall 1990 \{published data only\}}

Hempsall VJ, Robertson DR, Campbell MJ, Briggs RS. Orthopaedic geriatric care - is it effective? A prospective population-based comparison of outcome in fractured neck of femur. Journal of the Royal College of Physicians of London 1990;24(1):47-50.

\section{Kennie 1988 \{published data only\}}

Kennie DC, Reid J, Richardson IR, Kiamari AA, Kelt C. Effectiveness of geriatric rehabilitative care after fractures of the proximal femur in elderly women: A randomised clinical trial. BMJ 1988;297(6656):1083-6.

Marcantonio 2001 \{published data only (unpublished sought but not used)\}

Marcantonio ER. Systematic review data request [personal communication]. Email to: ER Marcantonio 16 March 2016.

Marcantonio ER, Flacker JM, Wright RJ, Resnick NM. Reducing delirium after hip fracture: A randomized trial. Journal of the American Geriatrics Society 2001;49(5):516-22.

\section{Naglie 2002 \{published data only\}}

Naglie G, Tansey C, Kirkland JL, Ogilvie-Harris DJ, Detsky AS, Etchells $\mathrm{E}$, et al. Interdisciplinary inpatient care for elderly people with hip fracture: A randomized controlled trial. CMAJ : Canadian Medical Association Journal 2002;167(1):25-32.

\section{Prestmo 2015 \{published data only\}}

* Prestmo A, Hagen G, Sletvold O, Helbostad JL, Thingstad P, Taraldsen $\mathrm{K}$, et al. Comprehensive geriatric care for patients with hip fractures: A prospective, randomised, controlled trial. Lancet 2015;385(9978):1623-33.

Taraldsen K, Thingstad P, Sletvold O, Saltvedt I, Lydersen S, Granat $\mathrm{MH}$, et al. The long-term effect of being treated in a geriatric ward compared to an orthopaedic ward on six measures of free-living physical behavior 4 and 12 months after a hip fracture - a randomised controlled trial. BMC Geriatrics 2015;15:160-7. [DOI: 10.1186/s12877-015-0153-6]

\section{Stenvall 2007 \{published data only\}}

Stenvall M, Berggren M, Lundström M, Gustafson Y, Olofsson B. A multidisciplinary intervention program improved the outcome after hip fracture for people with dementia--subgroup analyses of a randomized controlled trial. Archives of Gerontology and Geriatrics 2012;54(3):e284-9.

* Stenvall M, Olofsson B, Nyberg L, Lundström M, Gustafson Y. Improved performance in activities of daily living and mobility after a multidisciplinary postoperative rehabilitation in older people with femoral neck fracture: A randomized controlled trial with 1-year follow-up. Journal of Rehabilitation Medicine 2007;39(3):232-8. [DOI: 10.2340/16501977-0045]

Vidán 2005 \{published data only\}

Vidán M, Serra JA, Moreno C, Riquelme G, Ortiz J. Efficacy of a comprehensive geriatric intervention in older patients hospitalized for hip fracture: A randomized, controlled trial. Journal of the American Geriatrics Society 2005;53(9):1476-82. [DOI: 10.1111/j.1532-5415.2005.53466.x]

\section{References to studies excluded from this review}

\section{Albrand 2011 \{published data only\}}

Albrand G. Oncogeriatric support for breast cancer. Cahiers de l'Annee Gerontologique 2011;3:26-32.

\section{Applegate 1990 \{published data only\}}

Applegate WB, Miller ST, Graney MJ, Elam JT, Burns R, Akins DE. A randomized, controlled trial of a geriatric assessment unit in a community rehabilitation hospital. New England Journal of Medicine 1990;322(22):1572-8. [DOI: 10.1056/ nejm199005313222205]

\section{Bai 2003 \{published data only\}}

Bai B, Wang KZ, Liu WK, Song JH, Chen JC. Comprehensive treatment for old patients with hip fractures. Zhonghua Chuang Shang za Zhi [Chinese Journal of Traumatology] 2003;6(5):297-301.

\section{Barber 2012 \{published data only\}}

Barber J, Fox J, Doran H. The impact of a geriatrician on surgical wards. Age and Ageing 2012;41(Suppl 1):ii32. [DOI: 10.1093/ ageing/afs112]

Björkelund 2010 \{published data only\}

Björkelund KB, Hommel A, Thorngren KG, Gustafson L, Larsson S, Lundberg D. Reducing delirium in elderly patients with hip fracture: a multi-factorial intervention study. Acta Anaesthesiologica Scandinavica 2010;54(6):678-88. [DOI: 10.1111/j.1399-6576.2010.02232.x]

Day 2001 \{published data only\}

Day GA, Swanson C, Yelland C, Broome J, Dimitri K, Massey L, et al. Surgical outcomes of a randomized prospective trial involving patients with a proximal femoral fracture. Australian and New Zealand Journal of Surgery 2001;71(1):11-4. [DOI: 10.1046/j.1440-1622.2001.02019.x]

Fisher 2006 \{published data only\}

Fisher AA, Davis MW, Rubenach SE, Sivakumaran S, Smith PN, Budge MM. Outcomes for older patients with hip fractures: The 
impact of orthopedic and geriatric medicine cocare. Journal of Orthopaedic Trauma 2006;20(3):172-8.

Fukuse 2005 \{published data only\}

Fukuse T, Satoda N, Hijiya K, Fujinaga T. Importance of a comprehensive geriatric assessment in prediction of complications following thoracic surgery in elderly patients. Chest 2005;127(3):886-91.

\section{Galvard 1995 \{published data only\}}

Galvard H, Samuelsson SM. Orthopedic or geriatric rehabilitation of hip fracture patients: A prospective, randomized, clinically controlled study in Malmo, Sweden. Aging-Clinical and Experimental Research 1995;7(1):11-6.

\section{Ho 2009 \{published data only\}}

Ho WW, Kwan Dai DL, Liu KW, Chow KM, Lau E, Woo J, et al. To investigate the effect and cost-effectiveness of implementing an orthogeriatric intervention for elderly patients with acute hip fracture: the experience in Hong Kong. Journal of the American Geriatrics Society 2009;57(11):2153-4. [DOI: 10.1111/ j.1532-5415.2009.02529.x]

\section{Huddleston 2004 \{published data only\}}

Huddleston JM, Long KH, Naessens JM, Vanness D, Larson D, Trousdale R, et al. Medical and surgical comanagement after elective hip and knee arthroplasty: A randomized, controlled trial. Annals of Internal Medicine 2004;141(1):28-38.

\section{Huusko 2002 \{published data only\}}

Huusko TM, Karppi P, Avikainen V, Kautiainen H, Sulkava R. Intensive geriatric rehabilitation of hip fracture patients: a randomized, controlled trial. Acta Orthopaedica Scandinavica 2002;73(4):425-31. [DOI: 10.1080/00016470216324]

\section{Kimura 2013 \{published data only\}}

Kimura S, Lynch S, Lui DF, Butler A, Ramotshabi K, Hsu M, et al. Orthogeriatric involvement in the management of hip fracture improves functional outcome post operatively: Comprehesive Orthogeriatric Assessment Services for Trauma (COAST) trial. Irish Journal of Medical Science 2013;182:S59. [DOI: 10.1007/ s11845-013-0908-z]

\section{Leung 2010 \{published data only\}}

Leung A, Fong C, Mac KC, Ting C, Franklyn K, Gudjuhar A. Utility of an ortho-geriatric service: Hip fracture patient outcomes across three Melbourne metropolitan hospitals. Internal Medicine Journal 2010;40(Suppl 1):131. [DOI: 10.1111/ j.1445-5994.2010.02187.x]

\section{Lundström 2007 \{published data only\}}

Lundström M, Olofsson B, Stenvall M, Karlsson S, Nyberg L, Englund $U$, et al. Postoperative delirium in old patients with femoral neck fracture: A randomized intervention study. Aging Clinical and Experimental Research 2007;19(3):178-86.

\section{Miura 2009 \{published data only\}}

Miura LN, Dipiero AR, Homer LD. Effects of a geriatricianled hip fracture program: Improvements in clinical and economic outcomes. Journal of the American Geriatrics Society 2009;57(1):159-67. [DOI: 10.1111/j.1532-5415.2008.02069.x]

\section{Mouchoux 2010 \{published data only\}}

Mouchoux C, Duclos A, Krolak-Salmon P, Rippert P. Methodology for assessing the impact of a multidisciplinary prevention program to prevent postoperative delirium in the elderly. European Geriatric Medicine 2010;1:S63-4. [DOI: 10.1016/ j.eurger.2010.07.008]

Reid 1989 \{published data only\}

Reid J, Kennie DC. Geriatric rehabilitative care after fractures of the proximal femur: one year follow up of a randomised clinical trial. BMJ 1989;299(6690):25-6.

\section{Schnell 2010a \{published data only\}}

Schnell S, Friedman SM, Mendelson DA, Bingham KW, Kates SL. The 1-year mortality of patients treated in a hip fracture program for elders. Geriatric Orthopaedic Surgery \& Rehabilitation 2010;1(1):6-14. [DOI: 10.1177/2151458510378105]

\section{Tackett 2014 \{published data only\}}

Tackett JJ, Rosenthal RA. Proactive delirium management in geriatric surgical patients may increase ability to return patients home from the hospital. Journal of the American College of Surgeons 2014;219(Suppl):e104.

Taraldsen 2014 \{published data only\}

Taraldsen K, Sletvold O, Thingstad P, Saltvedt I, Granat MH, Lydersen S, et al. Physical behavior and function early after hip fracture surgery in patients receiving comprehensive geriatric care or orthopedic care: A randomized controlled trial. Journals of Gerontology. Series A, Biological Sciences and Medical Sciences 2014;69(3):338-45. [DOI: 10.1093/gerona/glt097]

\section{Watne 2014 \{published data only\}}

Watne LO, Torbergsen AC, Conroy S, Engedal K, Frihagen F, Hjorthaug GA, et al. The effect of a pre- and postoperative orthogeriatric service on cognitive function in patients with hip fracture: Randomized controlled trial (Oslo Orthogeriatric Trial). BMC Medicine 2014;12(1):63. [DOI: 10.1186/1741-7015-12-63]

\section{References to ongoing studies}

Baroni 2016 \{published data only\}

Baroni M, Pioli G, Boccardi V, Prenni V, Zengarini E, Conestabile della Staffa M, et al. The orthogeriatric management: An inseparable duo to foster appropriate care. Osteoporosis International 2016;1:S379. [DOI: 10.1007/s00198-016-3530-x]

\section{Brugel 2014 \{published data only\}}

Brugel L, Laurent M, Caillet P, Radenne A, Durand-Zaleski I, Martin $\mathrm{M}$, et al. Impact of comprehensive geriatric assessment on survival, function, and nutritional status in elderly patients with head and neck cancer: Protocol for a multicentre randomised controlled trial (EGeSOR). BMC Cancer 2014;14(1):427. [DOI: 10.1186/1471-2407-14-427] 


\section{Additional references}

\section{Bettelli 2011}

Bettelli G. Preoperative evaluation in geriatric surgery: comorbidity, functional status and pharmacological history. Minerva Anestesiologica 2011;77(6):637-46. [PUBMED: 21617627]

\section{Buecking 2013}

Buecking B, Timmesfeld N, Riem S, Bliemel C, Hartwig E, Friess T, et al. Early orthogeriatric treatment of trauma in the elderly: A systematic review and metaanalysis. Deutsches Arzteblatt International 2013;110(15):255-62.

\section{Covidence [Computer program]}

Veritas Health Innovation. Covidence. Melbourne, Australia: Veritas Health Innovation, accessed 15 May 2016.

\section{Deschodt 2013}

Deschodt M, Flamaing J, Haentjens P, Boonen S, Milisen K. Impact of geriatric consultation teams on clinical outcome in acute hospitals: a systematic review and meta-analysis. BMC Medicine 2013;11:48-60. [DOI: 10.1186/1741-7015-11-48]

\section{Eamer 2017b}

Eamer G, Saravana-Bawan B, van der Westhuizen B, Chambers T, Ohinmaa A, Khadaroo RG. Economic evaluations of comprehensive geriatric assessment in surgical patients: A systematic review. Journal of Surgical Research 2017;218:9-17. [DOI: 10.1016/j.jss.2017.03.041]

\section{Ellis 2017}

Ellis G, Gardner M, Tsiachristas A, Langhorne P, Burke O, Harwood RH, et al. Comprehensive geriatric assessment for older adults admitted to hospital. Cochrane Database of Systematic Reviews 2017, Issue 9. [DOI: 10.1002/14651858.CD006211.pub3]

\section{EPOC 2017a}

Effective Practice, Organisation of Care (EPOC). Screening, data extraction and management. Resources for review authors, 2017. Available at: http://epoc.cochrane.org/epoc-specificresources-review-authors.

\section{EPOC 2017b}

Effective Practice, Organisation of Care (EPOC). Suggested risk of bias criteria for EPOC reviews. Resources for review authors, 2017. Available at: http://epoc.cochrane.org/epoc-specificresources-review-authors.

\section{EPOC 2017c}

Cochrane Effective Practice and Organisation of Care (EPOC). EPOC worksheets for preparing a Summary of Findings (SoF) table using GRADE. EPOC Resources for review authors, 2017. Available at: http://epoc.cochrane.org/resources/epocresources-review-authors.

\section{Etzioni 2003}

Etzioni DA, Liu JH, Maggard MA, Ko CY. The aging population and its impact on the surgery workforce. Annals of Surgery 2003;238(2):170-7.

\section{Etzioni 2011}

Etzioni DA. Quality of care in surgery: the health services research perspective. Surgery 2011;150(5):881-6.

\section{Frondini 2010}

Frondini C, Munardelli M. Comprehensive care of elderly patients with hip fracture: The orthogeriatric model [Ortogeriatria: un nuovo modello di assistenza ai pazienti anziani con frattura di femore e comorbilita]. Italian journal of medicine 2010;4:105-110.

\section{Geriatric Review Syllabus 2006}

Beck JB, American Geriatrics Society. Geriatric Review Syllabus: A Core Curriculum in Geriatric Medicine. 6th Edition. New York, NY: American Geriatrics Society, 2006.

\section{GRADEpro GDT 2015 [Computer program]}

McMaster University (developed by Evidence Prime). GRADEpro GDT. Version accessed 15 May 2016. Hamilton (ON): McMaster University (developed by Evidence Prime), 2015.

\section{Grigoryan 2014}

Grigoryan KV, Javedan H, Rudolph JL. Ortho-geriatric care models and outcomes in hip fracture patients: a systematic review and meta-analysis. Journal of Orthopaedic Trauma 2014;28(3):49-55.

\section{Guyatt 2008}

Guyatt GH, Oxman AD, Vist GE, Kunz R, Falck-Ytter Y, AlonsoCoello $P$, et al. GRADE: an emerging consensus on rating quality of evidence and strength of recommendations. BMJ (Clinical research ed.) 2008;336(7650):924-6.

\section{Higgins 2011}

Higgins JPT, Green S (editors). Cochrane Handbook for Systematic Reviews of Interventions Version 5.1.0 (updated March 2011). The Cochrane Collaboration, 2011. Available from handbook.cochrane.org.

\section{Kammerlander 2010}

Kammerlander C, Roth T, Friedman SM, Suhm N, Luger TJ, Kammerlander-Knauer U, et al. Ortho-geriatric service - a literature review comparing different models. Osteoporosis International 2010;21(Suppl 4):S637-46.

\section{Lidsky 2012}

Lidsky ME, Thacker JK, Lagoo-Deenadayalan SA, Scarborough JE. Advanced age is an independent predictor for increased morbidity and mortality after emergent surgery for diverticulitis. Surgery 2012;152(3):465-72.

\section{Rao 1992}

Rao JNK, Scott AJ. A simple method for the analysis of clustered binary data. Biometrics 1992;48(2):577-85.

\section{Review Manager 2014 [Computer program]}

Nordic Cochrane Centre, The Cochrane Collaboration. Review Manager (RevMan 5). Version 5.3. Copenhagen: Nordic Cochrane Centre, The Cochrane Collaboration, 2014. 


\section{Rubenstein 1989}

Rubenstein L, Wieland D. Comprehensive geriatric assessment. Annual Review of Gerontology and Geriatrics 1989;9:145-92.

\section{Rubenstein 1991}

Rubenstein LZ, Stuck AE, Siu AL, Wieland D. Impact of geriatric evaluation and management programs on defined outcomes: overview of the evidence. Journal of the American Geriatrics Society 1991;39(9 Pt 2):8S-16S.

\section{Sabharwal 2015}

Sabharwal S, Wilson $\mathrm{H}$. Orthogeriatrics in the management of frail older patients with a fragility fracture. Osteoporosis International 2015;26(10):2387-99.

\section{Turrentine 2006}

Turrentine FE, Wang H, Simpson VB, Jones RS. Surgical risk factors, morbidity, and mortality in elderly patients. Journal of the American College of Surgeons 2006;203(6):865-77.

\section{References to other published versions of this review Eamer 2017a}

Eamer G, Taheri A, Chen SS, Daviduck Q, Chambers T, Shi X, et al. Comprehensive geriatric assessment for improving outcomes in elderly patients admitted to a surgical service. Cochrane Database of Systematic Reviews 2017, Issue 1. [DOI: 10.1002/14651858.CD012485]

* Indicates the major publication for the study

\section{CHARACTERISTICS OF STUDIES}

Characteristics of included studies [ordered by study ID]

Hempenius 2013

\begin{tabular}{ll} 
Study design: Randomized trial. \\
Study grouping: Parallel group. \\
Study duration: June 2007 to September 2010 \\
\hline Setting: Inpatient hospital \\
Country: The Neatherlands \\
Baseline characteristics \\
Geriatric care ( $\mathrm{n}=148)$ \\
- age: mean (77.5 years), standard deviation (SD) (6.7 years) \\
- female gender: $62.2 \%$ \\
- more than 2 comorbidities: $60.4 \%$ \\
Control (n=149) \\
- age: mean (77.6 years), SD (7.7) \\
- female gender: $65.8 \%$ \\
- more than 2 comorbidities: $59.6 \%$ \\
- Pre-admission assisted living or higher level of care: $20.1 \%$
\end{tabular}

Inclusion criteria: Aged over 65 years, elective surgery for a solid tumour and Groningen Frailty Indicator $>3$.

Exclusion criteria: Groningen Frailty Indicator $\leq 3$, unable to complete the study protocol and follow-up schedule, unable to fill in the questionnaires used in this study.

Pretreatment: No significant difference between groups.

Interventions

\section{Intervention characteristics}

Geriatric care 
- Intervention: "The geriatric team was supervised by a geriatrician, and helped devise the individual care plan. The preoperative comprehensive geriatric assessment by a geriatrician consisted of a medical history, physical examination and follow-up examinations on indication." "An individual treatment plan was drawn up paying specific attention to patient-related risk factors for delirium, namely, cognitive impairment, visual impairment, hearing impairment, malnutrition and impaired mobility. Preventive pharmacological measures were an optional but non-imperative part of the intervention protocol." "The patients in the intervention group were assessed daily by a geriatric nurse" and if issues arose a treatment plan was developed with the treatment team.

Control

- Intervention: "Patients in the usual-care group received standard [post-operative] care, which means that additional geriatric care was only provided at the request of the treating physician."

Outcomes

Outcomes reported in the study matching our primary and secondary outcomes

Mortality

- Outcome type: Dichotomous outcome.

- Direction: Lower is better.

Major complication - delirium

- Outcome type: Dichotomous outcome.

- Direction: Lower is better.

Discharge to an increased level of care

- Outcome type: Dichotomous outcome.

- Direction: Lower is better.

Major complication - cardiovascular

- Outcome type: Dichotomous outcome.

- Direction: Lower is better.

Major complication - pulmonary

- Outcome type: Adverse event.

- Direction: Lower is better.

Country: Netherlands.

Setting: University, teaching and community hospitals.

Author's name: Liesbeth Hempenius.

Institution: University of Groningen

Email: l.hempenius@umcg.nl

Address: University Center for Geriatric Medicine, University Medical Center Groningen, University of Groningen, Groningen, The Netherlands.

Notes

\section{Risk of bias}


Hempenius 2013 (Continued)

Random sequence genera- Low risk Interactive voice randomization service provided by the University Medical tion (selection bias)

Centre Groningen with stratification tumour type and location.

\begin{tabular}{l}
$\begin{array}{l}\text { Allocation concealment } \\
\text { (selection bias) }\end{array}$ \\
\hline
\end{tabular}

(selection bias)

\begin{tabular}{|c|c|c|}
\hline $\begin{array}{l}\text { Blinding of participants } \\
\text { and personnel (perfor- } \\
\text { mance bias) }\end{array}$ & High risk & $\begin{array}{l}\text { Participants from both arms were cared for by the same surgical team raising. } \\
\text { Geriatric consultation was provided to the intervention arm but the primary } \\
\text { outcome (delirium) is prone to bias. }\end{array}$ \\
\hline
\end{tabular}

\begin{tabular}{|c|c|c|}
\hline $\begin{array}{l}\text { Blinding of outcome as- } \\
\text { sessment (detection bias) } \\
\text { All outcomes }\end{array}$ & Unclear risk & $\begin{array}{l}\text { Quote: "The doctor diagnosing a possible delirium was, however, masked to } \\
\text { the study group". However, all other staff involved in the study were not blind- } \\
\text { ed. }\end{array}$ \\
\hline $\begin{array}{l}\text { Baseline demographics } \\
\text { between groups }\end{array}$ & Low risk & Demographics were similar between study arms. \\
\hline
\end{tabular}

Incomplete outcome data Low risk Low attrition.

(attrition bias)

All outcomes

\section{Protection from cross-con- High risk} tamination
Quote: "As mentioned before, the ward and research nurses were not blinded to the group to which a patient was randomised. This could lead to contamination, that is, additional interventions in the standard care group. In the case of contamination, one would expect a decrease in the difference in the incidence rate of delirium between the groups as the study progressed. As the lines in Figure 2 are not convergent, this argues against contamination."

\begin{tabular}{lll}
\hline $\begin{array}{l}\text { Selective reporting (re- } \\
\text { porting bias) }\end{array}$ & Low risk & No evidence of selective reporting. \\
\hline Other bias & Low risk & Judgement comment: Lower external validity due to strict inclusion criteria. \\
\hline
\end{tabular}

\section{Hempsall 1990}

Methods Study design: Randomized trial based on home address before admission

Study grouping: Parallel group.

Study duration: 16 months, unclear start date

Participants
Country: United Kingdom
Baseline characteristics
Geriatric care ( $n=82)$
- Age: median ( 83.0 years), range (66 to 98)
- Female: $81.7 \%$.
Control ( $n=73)$
- Age: median ( 83.0 years), range $(65$ to 97$)$
- Female: $78.1 \%$.


Hempsall 1990 (Continued)

Inclusion criteria: Fractured neck of femur aged over 65 years.

Exclusion criteria: No exclusion criteria were reported

Pretreatment: No difference between the groups.

Intervention characteristics
Geriatric care
- Intervention: "A medical assessment was carried out between 3 and 7 days post-operatively by a senior
registrar in geriatric medicine" "Patients were subsequently seen at least twice weekly and formally
reviewed every 2 weeks during their inpatient stay." Participants were transferred to the orthogeriatric
unit after the acute surgical recovery. Adverse events occurring before the eighth postoperative day
were not included in the analysis due to the delayed transfer to geriatric care.
Control
- Intervention: Participants received standard postoperative orthopedic care before being transferred
to a rehabilitation centre as needed.

Outcomes

Outcomes reported in the study matching our primary and secondary outcomes

Mortality

- Outcome type: Dichotomous outcome.

- Reporting: Fully reported.

- Direction: Lower is better.

Length of stay

- Outcome type: Continuous outcome.

- Reporting: Partially reported.

- Direction: Lower is better.

Discharge to an increased level of care

- Outcome type: Dichotomous outcome.

- Direction: Lower is better.

\begin{tabular}{ll}
\hline Identification & Sponsorship source \\
Country: UK. & Setting: General hospital. \\
& Author's name: VJ Hempsall. \\
& Institution: Departments of Community Medicine' and Geriatric Medicine. \\
& $\begin{array}{l}\text { Address: Department of Community Medicine, Royal Victoria Hospital, Shelley Road, Bournemouth } \\
\text { BH1 4HX. }\end{array}$ \\
\hline Notes & Authors' judgement Support for judgement \\
\hline Risk of bias & High risk \\
\hline Bias & Random sequence was generated based on the participants geographic origin. \\
\hline $\begin{array}{l}\text { Random sequence genera- } \\
\text { tion (selection bias) }\end{array}$
\end{tabular}


Hempsall 1990 (Continued)

$\begin{aligned} & \text { Allocation concealment } \\ & \text { (selection bias) }\end{aligned} \quad$ High risk Allocation was by geography or origin.

$\begin{array}{ll}\begin{array}{l}\text { Blinding of participants } \\ \text { and personnel (perfor- }\end{array} & \text { Low risk } \\ \text { Unable to blind participants from the nature of their study arm, however the } \\ \text { primary outcomes measured (mortality and LOS) are not prone to bias. }\end{array}$

mance bias)

All outcomes

\begin{tabular}{|c|c|c|}
\hline $\begin{array}{l}\text { Blinding of outcome as- } \\
\text { sessment (detection bias) }\end{array}$ & Low risk & $\begin{array}{l}\text { Unable to blind participants from the nature of their study arm, however the } \\
\text { primary outcomes measured (mortality and LOS) are not prone to bias. }\end{array}$ \\
\hline
\end{tabular}

$$
\text { utcomes }
$$

\begin{tabular}{lll}
\hline $\begin{array}{l}\text { Baseline demographics } \\
\text { between groups }\end{array}$ & Low risk & Populations were similar for reported demographic and medical variables. \\
\hline $\begin{array}{l}\text { Incomplete outcome data } \\
\text { (attrition bias) }\end{array}$ & Low risk & Low dropout rate. \\
All outcomes & & \\
\hline
\end{tabular}

Protection from cross-con- Unclear risk tamination
Quote: "A prospective comparison was made of the outcome of patients from two geographical sectors, both receiving identical initial treatment at Poole General Hospital."

\begin{tabular}{lll}
\hline $\begin{array}{l}\text { Selective reporting (re- } \\
\text { porting bias) }\end{array}$ & High risk & Did not report all outcomes that were expected. \\
\hline Other bias & Low risk & No other bias noted. \\
\hline
\end{tabular}

Kennie 1988

\begin{tabular}{ll}
\hline Methods & Study design: Randomized trial. \\
Study grouping: Parallel group. \\
Study duration: 18 months, unclear start d \\
\hline Setting: Inpatient hospital \\
Country: United Kingdom \\
Baseline characteristics \\
Geriatric care ( $\mathrm{n}=54)$ \\
- age: median (79 years), range (65 to 94) \\
- gender: $100 \%$ female \\
Control (n=54) \\
- age: median (84 years), range (66 to 94) \\
- gender: $100 \%$ female
\end{tabular}

Inclusion criteria: Women aged 65 years and over with proximal femur fracture.

Exclusion criteria: Died before becoming fit enough to enter the trial, pathological fractures, likely to be discharged within seven days of entering the trial, patient would return to nursing home after operation for further rehab, unfit for transfer. 
Kennie 1988 (Continued)

Pretreatment: Mental status.

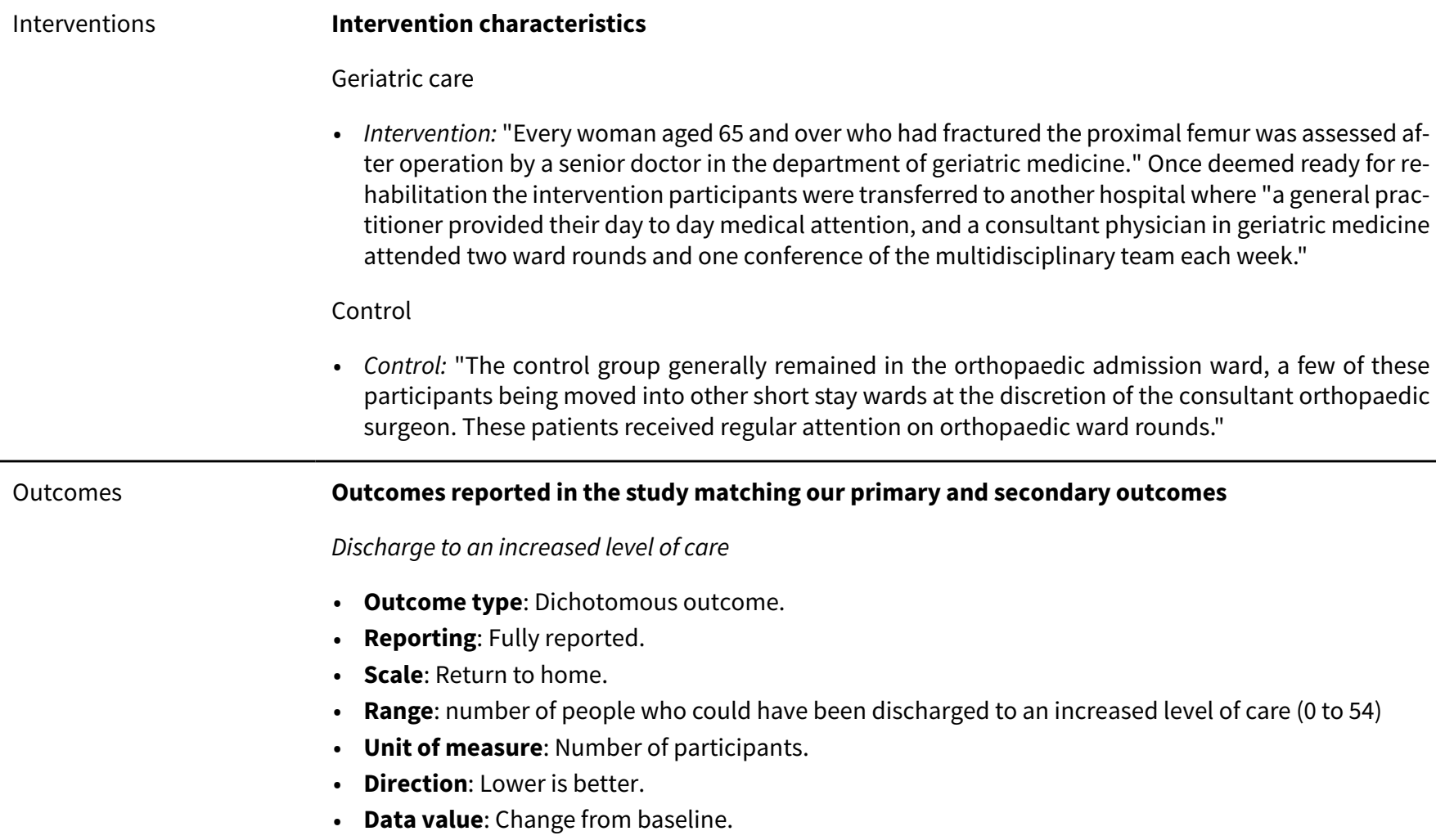

- Intervention: "Every woman aged 65 and over who had fractured the proximal femur was assessed after operation by a senior doctor in the department of geriatric medicine." Once deemed ready for rehabilitation the intervention participants were transferred to another hospital where "a general practitioner provided their day to day medical attention, and a consultant physician in geriatric medicine attended two ward rounds and one conference of the multidisciplinary team each week."

Control

- Control: "The control group generally remained in the orthopaedic admission ward, a few of these participants being moved into other short stay wards at the discretion of the consultant orthopaedic surgeon. These patients received regular attention on orthopaedic ward rounds."

\section{Risk of bias}

\begin{tabular}{lll}
\hline Bias & Authors' judgement & Support for judgement \\
\hline $\begin{array}{l}\text { Random sequence genera- } \\
\text { tion (selection bias) }\end{array}$ & Low risk & Sealed envelope randomization. \\
\hline $\begin{array}{l}\text { Allocation concealment } \\
\text { (selection bias) }\end{array}$ & Unclear risk & Random sequence allocation but unclear if it was concealed before allocation. \\
\hline
\end{tabular}

Blinding of participants Low risk Participants were not blinded, but the outcome (discharge location) is not very
and personnel (perfor- prone to bias.

mance bias)

All outcomes

Blinding of outcome assessment (detection bias)
Unclear risk

The authors do not describe how or who assessed outcomes. The authors make no mention of blinding the outcome assessors. 
Kennie 1988 (Continued)

All outcomes

\begin{tabular}{|c|c|c|}
\hline $\begin{array}{l}\text { Baseline demographics } \\
\text { between groups }\end{array}$ & Unclear risk & $\begin{array}{l}\text { The authors did not report comprehensive demographic data for the control } \\
\text { and experimental arms. }\end{array}$ \\
\hline
\end{tabular}

\begin{tabular}{|c|c|c|}
\hline $\begin{array}{l}\text { Incomplete outcome data } \\
\text { (attrition bias) } \\
\text { All outcomes }\end{array}$ & Low risk & Low attrition noted. \\
\hline $\begin{array}{l}\text { Protection from cross-con- } \\
\text { tamination }\end{array}$ & Low risk & $\begin{array}{l}\text { Judgement comment: Participants were treated in different hospitals after ini- } \\
\text { tial postoperative recovery. }\end{array}$ \\
\hline
\end{tabular}

\begin{tabular}{lll}
\hline $\begin{array}{l}\text { Selective reporting (re- } \\
\text { porting bias) }\end{array}$ & Low risk & No evidence of selective reporting. \\
\hline Other bias & Unclear risk & This study examined women and cannot necessarily be applied to men. \\
\hline
\end{tabular}

Marcantonio 2001

\begin{tabular}{ll}
\hline Methods & Study design: Randomized trial. \\
Study grouping: Parallel group. \\
Study duration: Not reported
\end{tabular}

\begin{tabular}{|c|c|}
\hline Participants & 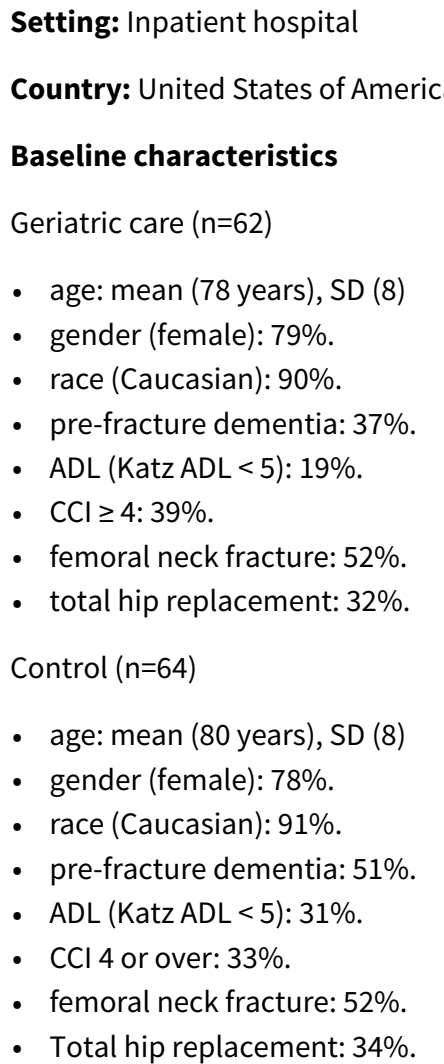 \\
\hline
\end{tabular}

Inclusion criteria: 65 years and older with primary hip fracture.

Exclusion criteria: Presence of metastatic cancer, life expectancy to less than 6 months, inability to obtain informed consent within 24 hours of surgery or 48 hours of admission. 
Pretreatment: Pre-fracture dementia and ADL impairment, both higher in the usual-care group.

Interventions
Geriatric care
- Intervention: "Subjects randomised to the intervention group underwent geriatrics consultation pre-
operatively or within 24 hours postoperatively. A geriatrician performed daily visits for the duration
of the hospitalization and made targeted recommendations based on a structured protocol."
Control
- Geriatric intervention: "The usual-care group received management by the orthopedics team, includ-
ing internal medicine or geriatrics consults on a reactive rather than proactive basis."

\section{Outcomes}

Outcomes reported in the study matching our primary and secondary outcomes

Major complication - delirium

- Outcome type: Dichotomous outcome.

- Reporting: Fully reported.

- Direction: Lower is better.

Major complication - severe delirium

- Outcome type: Dichotomous outcome.

- Reporting: Fully reported.

Days of delirium per episode

- Outcome type: Continuous outcome.

- Reporting: Fully reported.

Discharge to an increased level of care

- Outcome type: Dichotomous outcome.

- Reporting: Fully reported.

- Direction: Lower is better.

Sponsorship source: Older Americans Independence Center P60-AG08812-06, Charles Farnsworth Trust, Charles A King Trust.

Country: USA.

Setting: Tertiary academic center.

Authors name: Edward R Marcantonio.

Institution: Hebrew Rehabilitation Center for Aged.

Address: 1200 Centre Street, Boston, MA 02131. 16 years old and this information has been lost Marcantonio 2016 [pers comm].

\section{Risk of bias}

\begin{tabular}{lll}
\hline Bias & Authors' judgement & Support for judgement \\
\hline $\begin{array}{l}\text { Random sequence genera- } \\
\text { tion (selection bias) }\end{array}$ & Low risk & Sealed envelope randomisation. \\
\hline
\end{tabular}


Marcantonio 2001 (Continued)

$\begin{array}{ll}\begin{array}{l}\text { Allocation concealment } \\ \text { (selection bias) }\end{array} & \begin{array}{l}\text { No evidence that there was any deviation from standard randomisation tech- } \\ \text { niques. }\end{array}\end{array}$

\begin{tabular}{|c|c|c|}
\hline $\begin{array}{l}\text { Blinding of participants } \\
\text { and personnel (perfor- } \\
\text { mance bias) } \\
\text { All outcomes }\end{array}$ & Low risk & $\begin{array}{l}\text { Participants were not blinded to the intervention but the personnel assessing } \\
\text { delirium were blind to the arm and there was reportedly no inadvertent un- } \\
\text { blinding. }\end{array}$ \\
\hline $\begin{array}{l}\text { Blinding of outcome as- } \\
\text { sessment (detection bias) } \\
\text { All outcomes }\end{array}$ & Low risk & $\begin{array}{l}\text { The assessor of delirium was blinded to the intervention arm of each partici- } \\
\text { pant. }\end{array}$ \\
\hline $\begin{array}{l}\text { Baseline demographics } \\
\text { between groups }\end{array}$ & Low risk & $\begin{array}{l}\text { There were no significant differences between trial arms in measured vari- } \\
\text { ables. }\end{array}$ \\
\hline $\begin{array}{l}\text { Incomplete outcome data } \\
\text { (attrition bias) } \\
\text { All outcomes }\end{array}$ & Low risk & There was very low attrition in the trial. \\
\hline $\begin{array}{l}\text { Protection from cross-con- } \\
\text { tamination }\end{array}$ & High risk & $\begin{array}{l}\text { Quote: "Sixty-two of the } 126 \text { study patients were randomly assigned to proac- } \\
\text { tive geriatrics consultation." } \\
\text { Judgement comment: Orthopedics remained the primary physician in both } \\
\text { arms of the study, raising significant risk of cross-contamination. }\end{array}$ \\
\hline $\begin{array}{l}\text { Selective reporting (re- } \\
\text { porting bias) }\end{array}$ & Unclear risk & $\begin{array}{l}\text { There is no evidence of selective reporting; however, we requested addition- } \\
\text { al information from the authors including mortality. To date, the authors have } \\
\text { been unable to provide further information. }\end{array}$ \\
\hline Other bias & Unclear risk & $\begin{array}{l}\text { Quote: "intervention involved } 10 \text { modules and multiple possible recommenda- } \\
\text { tions. Although we have re- ported what was recommended and the percent } \\
\text { adherence, our design does not allow us to answer "What really made the dif- } \\
\text { ference?" }\end{array}$ \\
\hline
\end{tabular}

Naglie 2002

Methods

Study design: Randomized trial.

Study grouping: Parallel group.

Study duration: June 1993 to September 1997

Participants
Countring: Inpatient hospital
Baseline characteristics
Geriatric care ( $\mathrm{n}=141)$
- age: mean (83.8 years), SD (6.9)
- female gender: $77.3 \%$.
- mean Barthel index score: 82.9.
- walking aid use: $51.1 \%$.
- mean \# co-existing conditions: 2.0.
- intertrochanteric fracture: $53.2 \%$.
- time to surgery (days): 1.3.


Naglie 2002 (Continued)

- surgical procedure (hemi-arthroplasty): $31.9 \%$.

Control $(n=138)$

- age: mean (84.6 years), SD (7.3)

- female gender: $82.6 \%$.

- mean Barthel index score: 84.1 .

- walking aid use: $52.2 \%$

- mean \# co-existing conditions: 2.1 .

- intertrochanteric fracture: $60.9 \%$.

- time to surgery (days): 1.4 .

- surgical procedure (hemi-arthroplasty): $27.5 \%$.

Inclusion criteria: Aged at least 70 years, surgical repair of hip fracture.

Exclusion criteria: Fracture occurring in an acute care hospital, pathologic fracture, multiple trauma, previous surgery on the fractured hip, expected survival fewer than 6 months, residence in a nursing home and dependence on at least one person for ambulation before the fracture, or residence outside metropolitan Toronto.

Pretreatment: No statistically significant differences.

Interventions

\section{Intervention characteristics}

Geriatric care

- Intervention: "The principles of care on the interdisciplinary care ward included protocols and standardized orders to try to prevent problems common in older participants with hip fracture (e.g. delirium, urinary problems, constipation, pressure sores, venous thrombosis, polypharmacy, malnutrition and depression), early mobilization (full weight-bearing and twice-daily physiotherapy sessions Monday to Friday, whenever possible), early participation in self-care and individualized discharge planning (e.g. pre- discharge home visits, home care and additional rehabilitation in a rehabilitation facility). All nursing staff on the interdisciplinary care ward received specialized education about the care of older people with hip fracture. A physiotherapist, occupational therapist, clinical nurse specialist and social worker assigned to the ward routinely assessed all study patients within 72 hours and gave priority to these patients." "Participants in the interdisciplinary care group received routine postoperative surgical care, as well as daily medical care by a senior internal medicine resident supervised by an internist-geriatrician."

Control

- Intervention: "On the usual care ward, participants had access to allied health care professionals if a consultation was requested; they had limited access to an occupational therapist or a clinical nurse specialist."

- Outcome type: Dichotomous outcome.

- Reporting: Fully reported.

- Direction: Lower is better.

Length of stay

- Outcome type: Continuous outcome.

- Reporting: Fully reported.

Discharge to an increased level of care

- Outcome type: Dichotomous outcome. 
Naglie 2002 (Continued)

- Direction: Lower is better.

Identification Sponsorship source: Ontario Ministry of Health Physicians Services Incorporated Foundation.

Country: Canada.

Setting: Teaching hospital.

Authors name: Gary Naglie.

Institution: UniversityHealth Network and Mount Sinai Hospital, Toronto.

Email: gary.naglie@uhn.on.ca

Address: Toronto general hospital, Rm. EN G-233, 200 Elizabeth St, Toronto ON M5G 2C4.

\section{Notes}

\section{Risk of bias}

\begin{tabular}{lll}
\hline Bias & Authors' judgement & Support for judgement \\
\hline $\begin{array}{l}\text { Random sequence genera- } \\
\text { tion (selection bias) }\end{array}$ & Low risk & Stratified computer generated randomisation with block size of 4. \\
\hline $\begin{array}{l}\text { Allocation concealment } \\
\text { (selection bias) }\end{array}$ & Low risk & $\begin{array}{l}\text { Quote: "Orthopedic residents, who were blinded to block size, assigned the } \\
\text { patients to treatment group according to sequentially numbered, sealed, } \\
\text { opaque envelopes that were colour-coded by stratum." }\end{array}$ \\
\hline
\end{tabular}

Blinding of participants Low risk and personnel (perfor-

Participants and outcome assessors were not blind, however the primary outmance bias)

All outcomes comes are not prone to bias (mortality and discharge location).

\begin{tabular}{|c|c|c|}
\hline $\begin{array}{l}\text { Blinding of outcome as- } \\
\text { sessment (detection bias) }\end{array}$ & Low risk & $\begin{array}{l}\text { Primary outcomes are at low risk of detection bias, follow-up was conducted } \\
\text { by blinded research assistants. }\end{array}$ \\
\hline
\end{tabular}

All outcomes

\begin{tabular}{|c|c|c|}
\hline $\begin{array}{l}\text { Baseline demographics } \\
\text { between groups }\end{array}$ & Low risk & $\begin{array}{l}\text { Quote: "There were no statistically significant differences between the inter- } \\
\text { vention and control groups for any baseline characteristics". }\end{array}$ \\
\hline $\begin{array}{l}\text { Incomplete outcome data } \\
\text { (attrition bias) } \\
\text { All outcomes }\end{array}$ & Low risk & There is no evidence of incomplete outcome reporting. \\
\hline $\begin{array}{l}\text { Protection from cross-con- } \\
\text { tamination }\end{array}$ & Low risk & $\begin{array}{l}\text { Quote: "Staff in the interdisciplinary care ward held twice-weekly rounds to de- } \\
\text { velop and monitor treatment plans, whereas the usual care ward had no such } \\
\text { rounds. The staff on the inter- disciplinary care ward worked together for a 10- } \\
\text { month pilot period before the start of the study." }\end{array}$ \\
\hline $\begin{array}{l}\text { Selective reporting (re- } \\
\text { porting bias) }\end{array}$ & Low risk & There is no evidence of selective reporting, all expected outcomes are present. \\
\hline Other bias & Low risk & There is no evidence of additional bias. \\
\hline
\end{tabular}

Methods Study design: Randomized trial.


Prestmo 2015 (Continued)

\section{Study grouping: Parallel group.}

Study duration: April 18, 2008 to December 30, 2011

Setting: Inpatient hospital
Country: Norway
Baseline characteristics
Geriatric care ( $\mathrm{n}=198)$
- age: mean (83.4 years), SD (5.4)
- female gender: $73 \%$.
- hemi-arthroplasty: 38\%.
- Barthel index: 18.3.
- CCl: 2.3.
Control (n=199)
- age: mean (83.2 years), SD (6.4)
- female gender: $74 \%$.
- hemi-arthroplasty: $44 \%$.
- Barthel index: 18.1.
- CCl: 2.3.

Inclusion criteria: Hip fractures, home-dwelling people, aged 70 years or older who had been able to walk $10 \mathrm{~m}$ before the fracture.

Exclusion criteria: Pathological fractures, multiple traumas, short life expectancy, who were living permanently in nursing homes or already participating in the investigation.

Pretreatment: Baseline characteristics did not differ between the groups (table 2).

\section{Intervention characteristics}

\section{Geriatric care}

- Intervention: "The clinical pathway for comprehensive geriatric care was organised both before and after the operation as a systematic and interdisciplinary process, with an emphasis on comprehensive medical assessment and treatment, initiation of rehabilitation through mobilisation, and planning of discharge started early." Care was provided on a dedicated geriatric care unit. Orthopedic specialists did not routinely round on participants postoperatively.

Control

- Intervention: Participants received standard postoperative care on an orthopedic trauma ward and did not have routine access to a geriatrician.

Outcomes

\section{Outcomes reported in the study matching our primary and secondary outcomes}

Mortality

- Outcome type: Dichotomous outcome.

- Direction: Lower is better.

Length of stay

- Outcome type: Continuous outcome.

- Direction: Lower is better.

Total cost 
Prestmo 2015 (Continued)

- Outcome type: Continuous outcome.

- Reporting: Fully reported.

- Direction: Lower is better.

Discharge to an increased level of care

- Outcome type: Dichotomous outcome.

- Reporting: Fully reported.

- Direction: Lower is better.

Re-admission

- Outcome type: Dichotomous outcome.

- Direction: Lower is better.

Identification

Sponsorship source: Norwegian Research Council, Central Norway Regional Health Authority, St Olav Hospital Trust and Fund for Research and Innovation, Liaison Committee between Central Norway Regional Health Authority and the Norwegian University of Science and Technology, the Department of Neuroscience at the Norwegian University of Science and Technology, Foundation for Scientific and Industrial Research at the Norwegian Institute of Technology (SINTEF), and the Municipality of Trondheim.

Country: Norway.

Setting: Regional referral hospital.

Authors' names: Anders Prestmo, Gunhild Hagen.

Institution: Department of Neuroscience, Norwegian University of Science and Technology.

Email: ingvild.saltvedt@ntnu.no

Address: Post Box 8905, N-7491 Trondheim, Norway.

\section{Notes}

\section{Risk of bias}

\begin{tabular}{|c|c|c|}
\hline Bias & Authors' judgement & Support for judgement \\
\hline $\begin{array}{l}\text { Random sequence genera- } \\
\text { tion (selection bias) }\end{array}$ & Low risk & Computer randomisation. \\
\hline $\begin{array}{l}\text { Allocation concealment } \\
\text { (selection bias) }\end{array}$ & Low risk & Computer randomised with unknown block size in emergency department. \\
\hline $\begin{array}{l}\text { Blinding of participants } \\
\text { and personnel (perfor- } \\
\text { mance bias) } \\
\text { All outcomes }\end{array}$ & Unclear risk & $\begin{array}{l}\text { The outcomes studied are somewhat prone to performance bias and the man- } \\
\text { uscript does not clarify if the assessors were blinded to the intervention arm. }\end{array}$ \\
\hline $\begin{array}{l}\text { Blinding of outcome as- } \\
\text { sessment (detection bias) } \\
\text { All outcomes }\end{array}$ & Unclear risk & $\begin{array}{l}\text { Quote: "Assessments were done by assessors who were not associated with } \\
\text { patient care." } \\
\text { Judgement comment: Does not say if assessors were blinded. }\end{array}$ \\
\hline $\begin{array}{l}\text { Baseline demographics } \\
\text { between groups }\end{array}$ & Low risk & Quote: "Baseline characteristics did not differ between the groups". \\
\hline $\begin{array}{l}\text { Incomplete outcome data } \\
\text { (attrition bias) }\end{array}$ & Low risk & All expected outcomes were reported. \\
\hline
\end{tabular}


Prestmo 2015 (Continued)

All outcomes

Protection from cross-con- Low risk tamination
Selective reporting (reporting bias)
Each study arm was cared for on a different ward by separate staff including separate physicians.

Other bias Low risk No other risk of bias was noted.

Stenvall 2007

Methods

Study design: Randomized trial.

Study grouping: Parallel group.

Study duration: May 2000 to December 2003

Participants
Country: Sweeden
Baseline characteristics
Geriatric care ( $\mathrm{n}=102)$
- age: mean (82.3 years), SD (6.6)
- female gender: $72.5 \%$
Control ( $\mathrm{n}=97)$
- age: mean (82.0 years), SD (5.9)
- female gender: $76.3 \%$

Inclusion criteria: Femoral neck fracture, aged $\geq 70$ years.

Exclusion criteria: Severe rheumatoid arthritis, severe hip osteoarthritis, pathological fracture, severe kidney failure, bedridden before the fracture.

Pretreatment: Significant depression in control group.

Interventions

\section{Intervention characteristics}

\section{Geriatric care}

- intervention: "The intervention ward was a geriatric unit specializing in geriatric orthopaedic patients. The staff worked in teams to apply comprehensive geriatric assessments and rehabilitation. Active prevention, detection and treatment of postoperative complications, such as falls, delirium, pain, decubital ulcers, and malnutrition, were systematically implemented daily during the hospitalisation. Early mobilization, with daily training, was provided by physiotherapists, occupational therapists and care staff during the hospital stay."

Control

- intervention: "The control ward was a specialist orthopaedic unit following conventional postoperative routines."

Outcomes

\section{Outcomes reported in the study matching our primary and secondary outcomes}

Length of stay 
Stenvall 2007 (Continued)

- Outcome type: Continuous outcome.

Mortality

- Outcome type: Dichotomous outcome.

Discharge to an increased level of care

- Outcome type: Dichotomous outcome.

- Direction: Lower is better.

Re-admission

- Outcome type: Dichotomous outcome.

- Direction: Lower is better.

Identification

Sponsorship source: Vårdal Foundation", the Joint Com-mittee of the Northern Health Region of Sweden (Visare Norr), the JC Kempe Memorial Foundation, the Dementia Fund, the Foundation of the Medical Faculty, the Borgerskapet of Umeå Research Foundation, the Erik and Anne-Marie Detlof's Foundation, University of Umeå and the County Council of Västerbotten ("Dagmar", "FoU", and "Äldre Centrum Västerbotten") and the Swedish Research Council, grants K2002-27VP-14165-02B, K2002-27VX-14172-02B, K2005-27VX-15357-01A.

Country: Sweden.

Setting: University Hospital.

Authors name: Michael Stenvall.

Institution: Umeå University.

Email: michael.stenvall@germed.umu.se

Address: Department of Community Medicine and Rehabilitation, Geriatric Medicine, Umeå University, SE-901 87 Umeå, Sweden.

Notes

\section{Risk of bias}

\begin{tabular}{lll}
\hline Bias & Authors' judgement & Support for judgement \\
\hline $\begin{array}{l}\text { Random sequence genera- } \\
\text { tion (selection bias) }\end{array}$ & Low risk & Opaque sealed envelope randomisation. \\
\hline $\begin{array}{l}\text { Allocation concealment } \\
\text { (selection bias) }\end{array}$ & Low risk & $\begin{array}{l}\text { Judgement comment: opaque sealed envelopes to allocate participants. En- } \\
\text { velopes were opened immediately before surgery to ensure similar pre-opera- } \\
\text { tive treatment. }\end{array}$ \\
\hline
\end{tabular}

Blinding of participants Low risk Outcomes assessed are unlikely to be influenced by bias.

and personnel (perfor-

mance bias)

All outcomes

\begin{tabular}{lll}
\hline $\begin{array}{l}\text { Blinding of outcome as- } \\
\text { sessment (detection bias) }\end{array}$ & Low risk & $\begin{array}{l}\text { Quote: "The assessors were aware of the study-group allocation during the } \\
\text { study period." However the outcomes measured are not prone to bias (mortal- } \\
\text { All outcomes }\end{array}$ \\
ity, re-admission and discharge location).
\end{tabular}

Baseline demographics Low risk between groups

There were small differences at baseline between groups, however all outcome were analyzed after controlling for these differences. 
Stenvall 2007 (Continued)
Incomplete outcome data
Low risk
All expected outcomes were reported.
(attrition bias)

All outcomes

Protection from cross-con- Unclear risk tamination
Judgement comment: Staff were aware of the study but participants were not cared for on the same ward. It is unclear if the orthopedic surgeons were actively involved in the postoperative care of the intervention cohort.

\begin{tabular}{lll}
\hline $\begin{array}{l}\text { Selective reporting (re- } \\
\text { porting bias) }\end{array}$ & Low risk & There is no evidence of selective reporting. \\
\hline Other bias & Low risk & No other evidence of bias was noted. \\
\hline
\end{tabular}

Vidán 2005

Methods

Study design: Randomized trial.

Study grouping: Parallel group

Study duration: February 1, 1997 to December 15, 1998

Setting: Inpatient hospital
Country: Spain
Baseline characteristics
Geriatric care (n=155)
- age: mean (81.1 years), SD (7.8)
- female gender: $85.1 \%$
- mean \# co-existing conditions: 2.8.
- hemi-arthroplasty: $37.4 \%$.
- hours to surgery: 75.8.
Control (n=164)
- age: mean (82.6 years), SD (7.4)
- female gender: $78.7 \%$.
- mean \# co-existing conditions: 2.9.
- hemi-arthroplasty: $32.3 \%$
- hours to surgery: 78.5.

Inclusion criteria: Aged 65 years and over, who were admitted to Hospital General Universitario between 1 February and 15 December 1997 for acute hip fracture surgery.

Exclusion criteria: Inability to walk before the fracture, dependency in all basic ADLs (ADL50), pathological hip fracture and known terminal illnesses, defined as those associated with a life expectancy of fewer than 12 months.

Pretreatment: No significant differences.

Interventions

\section{Intervention characteristics}

Geriatric care

- Intervention: "All patients had an orthopedic surgeon and a nurse assigned when they were admitted to hospital. The intervention and control groups shared the same orthopedic wards and used the same 
Vidán 2005 (Continued)

hospital-wide support services, including physical therapy and social work. A geriatric team that included a geriatrician, a rehabilitation specialist, and a specific social worker also treated participants enrolled in the intervention group. Briefly, the intervention consisted of a complete geriatric evaluation to identify and quantify medical and psychosocial problems and functional capability to elaborate a comprehensive therapeutic plan. A geriatrician visited the participants daily and was responsible for medical care. The rehabilitation specialist planned the schedule and the intensity and duration of physical therapy. The social worker assessed the social environment network and gave advice needed to improve the social support when necessary."

Control

- Intervention: "The surgeon and the orthopedic nurses managed participants allocated to the usual care group, with counselling from different specialists as needed if medical problems occurred. The orthopedic surgeon made the decision of discharge moment in both groups."

\section{Outcomes}

\section{Outcomes reported in the study matching our primary and secondary outcomes}

Mortality

- Outcome type: Dichotomous outcome.

- Reporting: Fully reported.

- Direction: Lower is better.

Major complication

- Outcome type: Dichotomous outcome.

- Reporting: Fully reported.

- Direction: Lower is better.

- Notes: Confusion, pressure sores, heart failure, pneumonia, DVT/PE, MI, arrhythmia.

Major complication - delirium

- Outcome type: Dichotomous outcome.

- Reporting: Fully reported.

- Direction: Lower is better.

Length of stay

- Outcome type: Continuous outcome.

- Reporting: Fully reported.

- Direction: Lower is better.

- Notes: Acute stay only. (FIS 97/0542), Ministerio de Sanidad, Spain.

Country: Spain.

Setting: University hospital.

Author's name: Maite Vidan.

Institution: Hospital General Universitario Gregorio Maran.

Email: mvidan.hgugm@salud.madrid.org

Address: Department of Geriatric Medicine, Hospital General Universitario Gregorio, Dr. Esquerdo 46, 28007, Spain. 
Vidán 2005 (Continued)

Risk of bias

\begin{tabular}{|c|c|c|}
\hline Bias & Authors' judgement & Support for judgement \\
\hline \multirow[t]{4}{*}{$\begin{array}{l}\text { Random sequence genera- } \\
\text { tion (selection bias) }\end{array}$} & Unclear risk & $\begin{array}{l}\text { Quote: "After baseline assessment, patients were randomised to the interven- } \\
\text { tion or usual care group," }\end{array}$ \\
\hline & & $\begin{array}{l}\text { Quote: "Homogeneity of groups according to stratified randomisation was } \\
\text { proved." }\end{array}$ \\
\hline & & $\begin{array}{l}\text { Quote: "After baseline assessment, patients were randomised to the interven- } \\
\text { tion or usual care group, stratified by pre-fracture ADL level: inde- pendent in } \\
\text { four or more or less than four ADLs." }\end{array}$ \\
\hline & & Judgement comment: Does not explain randomization procedure. \\
\hline $\begin{array}{l}\text { Allocation concealment } \\
\text { (selection bias) }\end{array}$ & Unclear risk & It is unclear how randomization was performed. \\
\hline $\begin{array}{l}\text { Blinding of participants } \\
\text { and personnel (perfor- } \\
\text { mance bias) } \\
\text { All outcomes }\end{array}$ & Unclear risk & $\begin{array}{l}\text { Composit outcome includes delirium and it is not clear if the assessor was } \\
\text { blinded. Outher outcomes, including LOS and mortality are not prone to this } \\
\text { bias. }\end{array}$ \\
\hline $\begin{array}{l}\text { Blinding of outcome as- } \\
\text { sessment (detection bias) } \\
\text { All outcomes }\end{array}$ & Unclear risk & $\begin{array}{l}\text { Quote: "The baseline assessment was made using personal patient interviews } \\
\text { on admission, before randomisation." but it is unclear if the chart review was } \\
\text { conducted by a blinded individual. }\end{array}$ \\
\hline $\begin{array}{l}\text { Baseline demographics } \\
\text { between groups }\end{array}$ & Low risk & No difference between arms at baseline. \\
\hline $\begin{array}{l}\text { Incomplete outcome data } \\
\text { (attrition bias) } \\
\text { All outcomes }\end{array}$ & Unclear risk & Attrition is not reported. \\
\hline $\begin{array}{l}\text { Protection from cross-con- } \\
\text { tamination }\end{array}$ & High risk & $\begin{array}{l}\text { The intervention and control arms shared the same wards and used the same } \\
\text { allied health services. }\end{array}$ \\
\hline $\begin{array}{l}\text { Selective reporting (re- } \\
\text { porting bias) }\end{array}$ & Low risk & No evidence of selective reporting. \\
\hline Other bias & Low risk & No other sources of bias identified \\
\hline
\end{tabular}

ADL: activities of daily living; CCI: Charlson Comorbidity Index; DVT: deep vein thrombosis; LOS - length of stay; MI: myocardial infarction; PE: pulmonary embolism; SD: standard deviation

Characteristics of excluded studies [ordered by study ID]

\begin{tabular}{ll}
\hline Study & Reason for exclusion \\
\hline Albrand 2011 & Wrong setting. \\
\hline Applegate 1990 & Wrong intervention. \\
\hline Bai 2003 & Wrong outcomes. \\
\hline
\end{tabular}




\begin{tabular}{|c|c|}
\hline Study & Reason for exclusion \\
\hline Barber 2012 & Wrong outcomes. \\
\hline Björkelund 2010 & No full geriatric assessment. \\
\hline Day 2001 & Wrong patient population. \\
\hline Fisher 2006 & Wrong patient population. \\
\hline Fukuse 2005 & Wrong patient population. \\
\hline Galvard 1995 & Wrong patient population. \\
\hline Ho 2009 & Wrong comparator. \\
\hline Huddleston 2004 & Wrong intervention. \\
\hline Huusko 2002 & Wrong patient population. \\
\hline Kimura 2013 & Wrong patient population. \\
\hline Leung 2010 & Adult population. \\
\hline Lundström 2007 & Wrong outcomes. \\
\hline Miura 2009 & Wrong patient population. \\
\hline Mouchoux 2010 & Study was terminated earlier due to insufficient enrollment of participants. \\
\hline Reid 1989 & Wrong outcomes. \\
\hline Schnell 2010a & Adult population. \\
\hline Tackett 2014 & Wrong outcomes. \\
\hline Taraldsen 2014 & Wrong outcomes. \\
\hline Watne 2014 & Adult population. \\
\hline
\end{tabular}

Characteristics of ongoing studies [ordered by study ID]

Baroni 2016

\begin{tabular}{ll}
\hline Trial name or title & Unknown \\
\hline Methods & $\begin{array}{l}\text { Randomized controlled comparison of orthopedic versus orthogeriatric care of older people with } \\
\text { hip fracture. }\end{array}$ \\
\hline Participants & $\begin{array}{l}\text { People aged } 65 \text { years and older, who could walk outdoors before fracture, presenting with low-im- } \\
\text { pact hip fracture. }\end{array}$ \\
\hline Interventions & Orthogeriatric care compared to usual orthopedic care. \\
\hline
\end{tabular}


Baroni 2016 (Continued)

Outcomes

Estimate the effect of orthogeriatric co management on the prescription of appropriate anti fracture therapy at hospital discharge. The secondary aim of the study is to evaluate adherence to treatments, mobility and functional independence at 6 and 12 months from surgery.

\begin{tabular}{ll}
\hline Starting date & Unknown. \\
\hline Contact information & Unknown. \\
\hline Notes & University of Perugia, Perugia, Italy. \\
\hline
\end{tabular}

Brugel 2014

\begin{tabular}{|c|c|}
\hline Trial name or title & EGeSOR \\
\hline Methods & Open-label, multicenter, randomised, controlled, parallel-group trial. \\
\hline Participants & $\begin{array}{l}\text { People aged } 70 \text { years or older and receiving standard care for head and neck squamous cell carci- } \\
\text { noma. }\end{array}$ \\
\hline Interventions & Comprehensive geriatric assessment and standardized geriatric care. \\
\hline Outcomes & $\begin{array}{l}\text { The primary endpoint, assessed after } 6 \text { months, is a composite criterion including death, function- } \\
\text { al impairment [Activities of Daily Living score decrease } \geq 2 \text {, and weight loss } \geq 10 \% \text {. Secondary end- } \\
\text { points include progression-free survival, unscheduled admissions, quality of life, treatment toxici- } \\
\text { ties, costs, and completion of the planned cancer treatment. }\end{array}$ \\
\hline Starting date & Unknown \\
\hline Contact information & elena.paillaud@hmn.aphp.fr \\
\hline Notes & \\
\hline
\end{tabular}

\section{DATA AND ANALYSES}

\section{Comparison 1. Geriatric care versus control}

\begin{tabular}{lllll}
\hline $\begin{array}{l}\text { Outcome or subgroup } \\
\text { title }\end{array}$ & No. of studies & $\begin{array}{l}\text { No. of partici- } \\
\text { pants }\end{array}$ & Statistical method & Effect size \\
\hline 1 Mortality & 5 & 1316 & Risk Ratio (IV, Random, 95\% Cl) & $0.85[0.68,1.05]$ \\
\hline 1.14 to 6 months & 2 & 476 & Risk Ratio (IV, Random, 95\% Cl) & $0.74[0.46,1.20]$ \\
\hline 1.21 year & 3 & 840 & Risk Ratio (IV, Random, 95\% Cl) & $0.87[0.69,1.11]$ \\
\hline $\begin{array}{l}2 \text { Discharge to an in- } \\
\text { creased level of care }\end{array}$ & 5 & 941 & Risk Ratio (IV, Random, 95\% Cl) & $0.71[0.55,0.92]$ \\
\hline 2.1 Discharge & 1 & & Risk Ratio (IV, Random, 95\% Cl) & $0.31[0.12,0.79]$ \\
\hline
\end{tabular}




\begin{tabular}{|c|c|c|c|c|}
\hline $\begin{array}{l}\text { Outcome or subgroup } \\
\text { title }\end{array}$ & No. of studies & $\begin{array}{l}\text { No. of partici- } \\
\text { pants }\end{array}$ & Statistical method & Effect size \\
\hline 2.24 to 6 months & 2 & 344 & Risk Ratio (IV, Random, 95\% CI) & $0.81[0.54,1.21]$ \\
\hline 2.31 year & 2 & 489 & Risk Ratio (IV, Random, 95\% Cl) & $0.73[0.52,1.03]$ \\
\hline 3 Length of stay & 5 & & Mean Difference (IV, Random, 95\% CI) & Totals not selected \\
\hline $\begin{array}{l}3.1 \text { Acute hospital dis- } \\
\text { charge }\end{array}$ & 1 & & Mean Difference (IV, Random, 95\% CI) & $0.0[0.0,0.0]$ \\
\hline 3.2 Discharge & 4 & & Mean Difference (IV, Random, 95\% CI) & $0.0[0.0,0.0]$ \\
\hline 4 Re-admission & 3 & 741 & Risk Ratio (IV, Random, 95\% Cl) & $1.00[0.76,1.32]$ \\
\hline 4.11 to 3 months & 1 & 225 & Risk Ratio (IV, Random, 95\% Cl) & $1.25[0.74,2.09]$ \\
\hline 4.21 year & 2 & 516 & Risk Ratio (IV, Random, 95\% Cl) & $0.95[0.67,1.33]$ \\
\hline 5 Major complication & 2 & & Risk Ratio (IV, Fixed, 95\% CI) & Totals not selected \\
\hline 5.1 Discharge & 2 & & Risk Ratio (IV, Fixed, 95\% CI) & $0.0[0.0,0.0]$ \\
\hline $\begin{array}{l}6 \text { Major complication - } \\
\text { delirium }\end{array}$ & 3 & & Risk Ratio (IV, Random, 95\% CI) & Subtotals only \\
\hline 6.1 Discharge & 3 & 705 & Risk Ratio (IV, Random, 95\% Cl) & $0.75[0.60,0.94]$ \\
\hline
\end{tabular}

Analysis 1.1. Comparison 1 Geriatric care versus control, Outcome 1 Mortality.

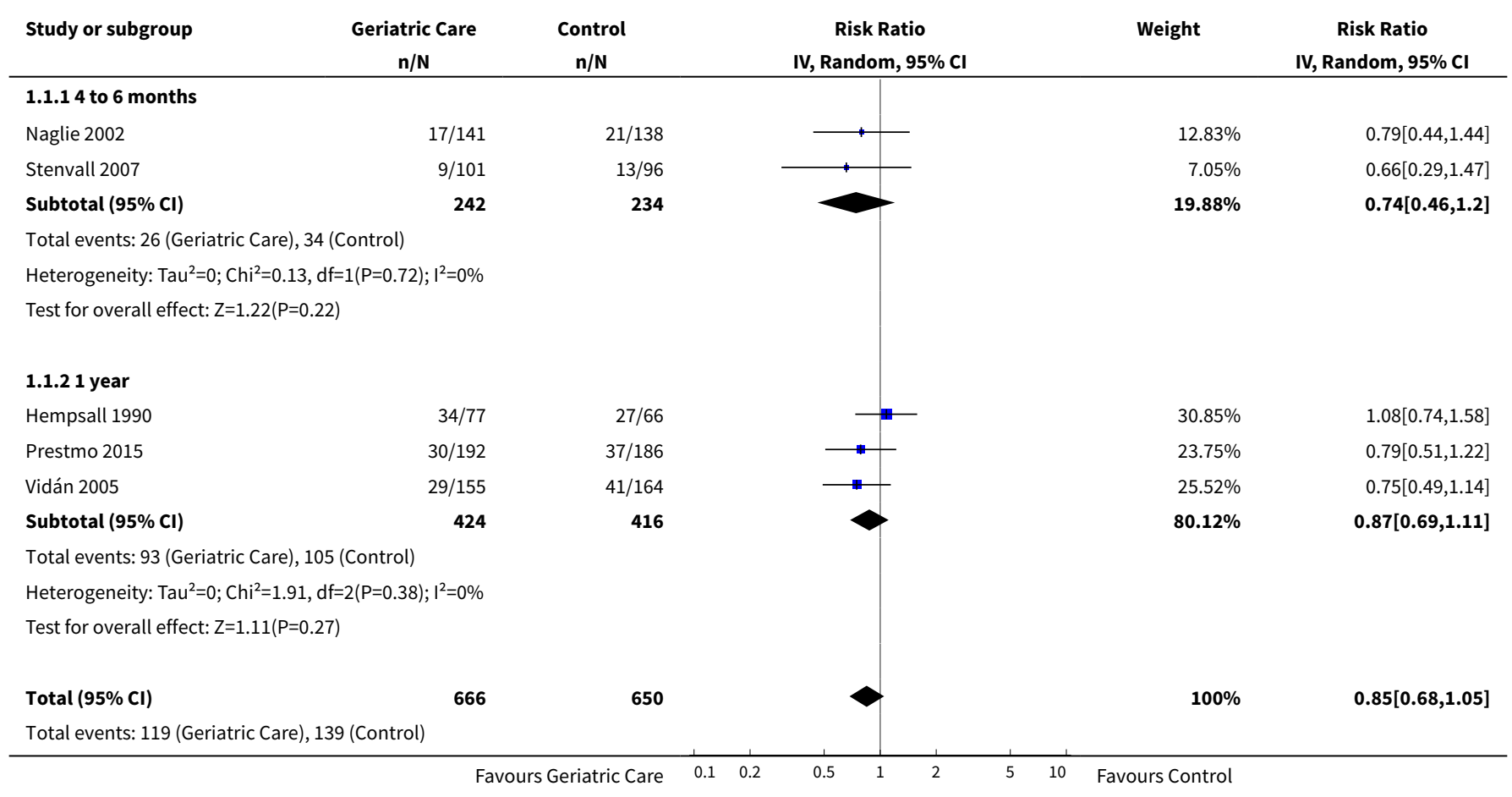




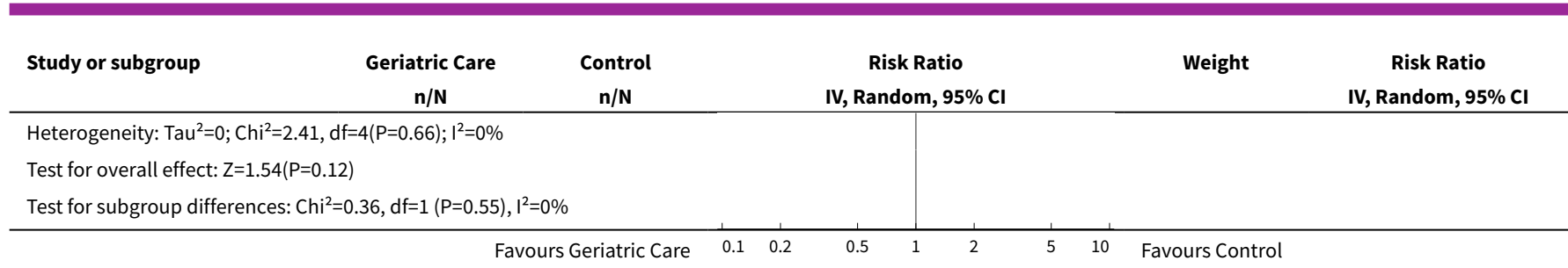

\section{Analysis 1.2. Comparison 1 Geriatric care versus control, Outcome 2 Discharge to an increased level of care.}

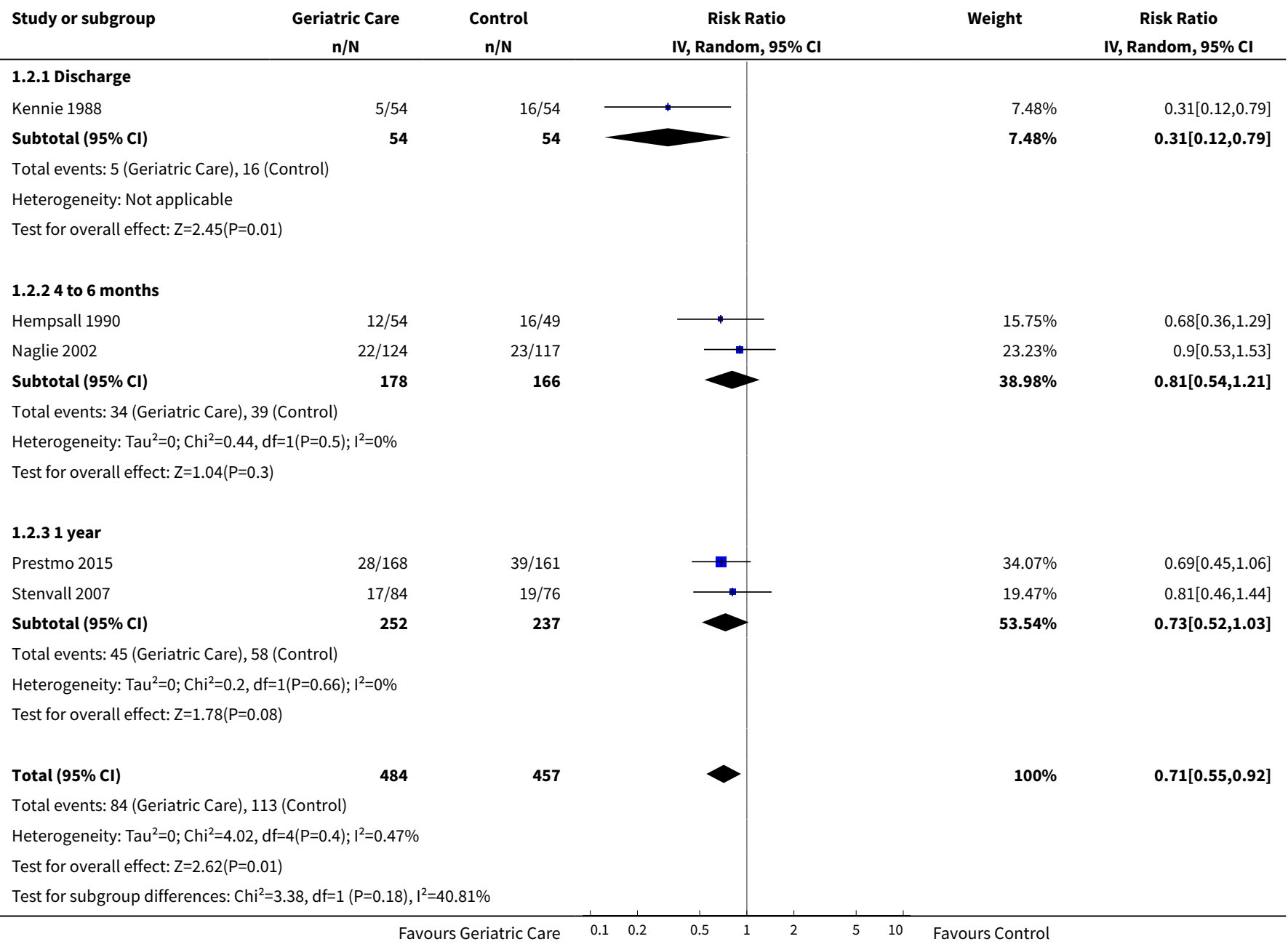

Analysis 1.3. Comparison 1 Geriatric care versus control, Outcome 3 Length of stay.

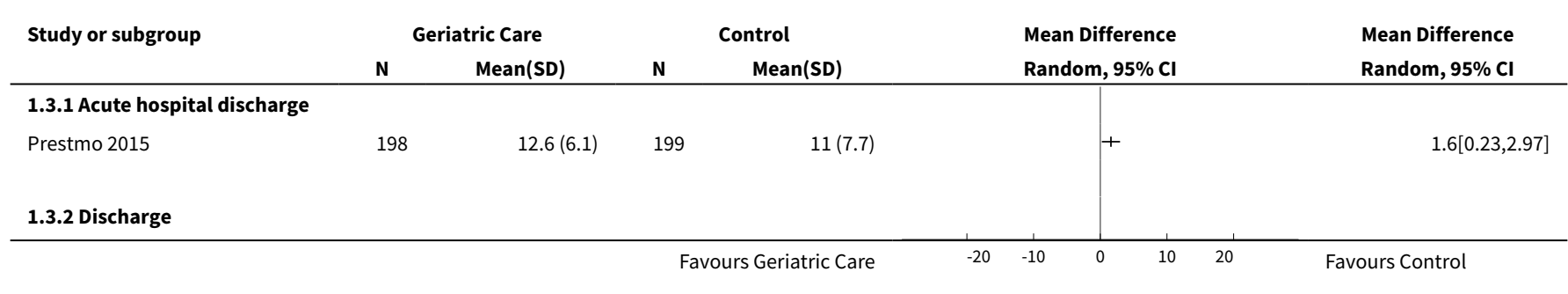




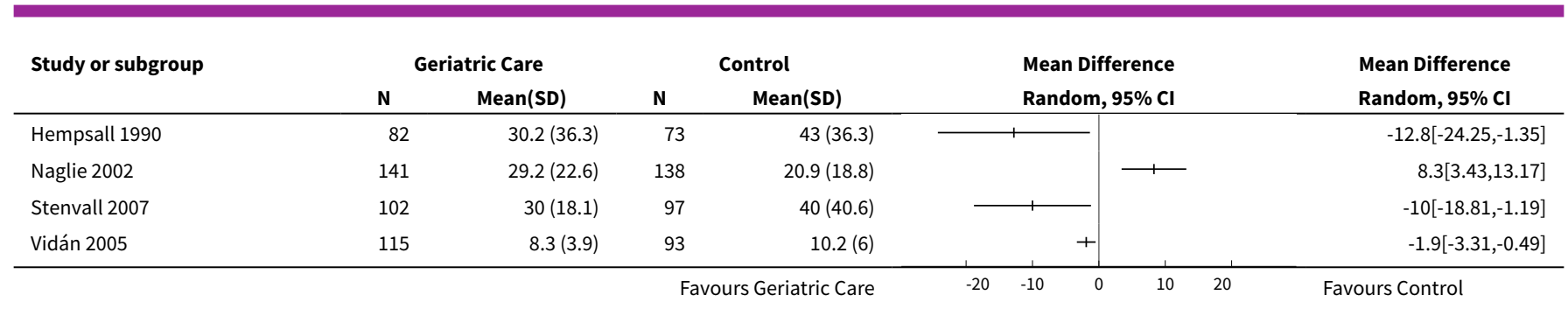

Analysis 1.4. Comparison 1 Geriatric care versus control, Outcome 4 Re-admission.

\begin{tabular}{|c|c|c|c|c|c|}
\hline Study or subgroup & $\begin{array}{c}\text { Geriatric Care } \\
\mathbf{n} / \mathbf{N} \\
\end{array}$ & $\begin{array}{c}\text { Control } \\
n / N\end{array}$ & $\begin{array}{c}\text { Risk Ratio } \\
\text { IV, Random, } 95 \% \mathrm{CI}\end{array}$ & Weight & $\begin{array}{c}\text { Risk Ratio } \\
\text { IV, Random, } 95 \% \mathrm{CI}\end{array}$ \\
\hline \multicolumn{6}{|l|}{ 1.4.1 1 to 3 months } \\
\hline Hempenius 2013 & $24 / 105$ & $22 / 120$ & 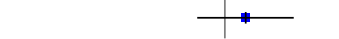 & $21.44 \%$ & $1.25[0.74,2.09]$ \\
\hline Subtotal $(95 \% \mathrm{Cl})$ & 105 & 120 & & $21.44 \%$ & $1.25[0.74,2.09]$ \\
\hline \multicolumn{6}{|c|}{ Total events: 24 (Geriatric Care), 22 (Control) } \\
\hline \multicolumn{6}{|c|}{ Heterogeneity: Not applicable } \\
\hline \multicolumn{6}{|l|}{ 1.4.2 1 year } \\
\hline Prestmo 2015 & $54 / 179$ & $66 / 177$ & $\rightarrow$ & $44 \%$ & $0.81[0.6,1.09]$ \\
\hline Stenvall 2007 & $38 / 84$ & $30 / 76$ & & $34.56 \%$ & $1.15[0.8,1.65]$ \\
\hline Subtotal $(95 \% \mathrm{Cl})$ & 263 & 253 & & $78.56 \%$ & $0.95[0.67,1.33]$ \\
\hline \multicolumn{6}{|c|}{ Total events: 92 (Geriatric Care), 96 (Control) } \\
\hline \multicolumn{6}{|c|}{ Test for overall effect: $Z=0.32(P=0.75)$} \\
\hline Total $(95 \% \mathrm{Cl})$ & 368 & 373 & & $100 \%$ & $1[0.76,1.32]$ \\
\hline \multicolumn{6}{|c|}{ Total events: 116 (Geriatric Care), 118 (Control) } \\
\hline \multicolumn{6}{|c|}{ Heterogeneity: $\mathrm{Tau}^{2}=0.02 ; \mathrm{Chi}^{2}=3.18, \mathrm{df}=2(\mathrm{P}=0.2) ; \mathrm{I}^{2}=37.1 \%$} \\
\hline \multicolumn{6}{|c|}{ Test for overall effect: $Z=0.01(P=0.99)$} \\
\hline Test for subgroup dif & $.77, \mathrm{df}=1(\mathrm{P}=0.38)$, & & & & \\
\hline
\end{tabular}

Analysis 1.5. Comparison 1 Geriatric care versus control, Outcome 5 Major complication.

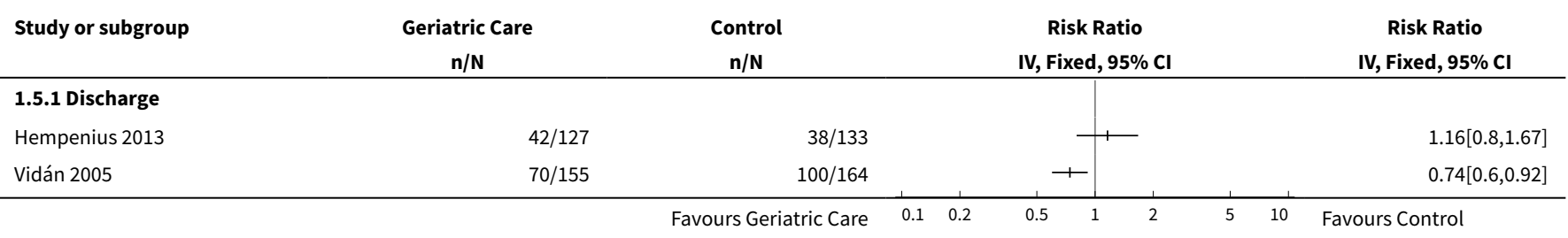


Analysis 1.6. Comparison 1 Geriatric care versus control, Outcome 6 Major complication - delirium.

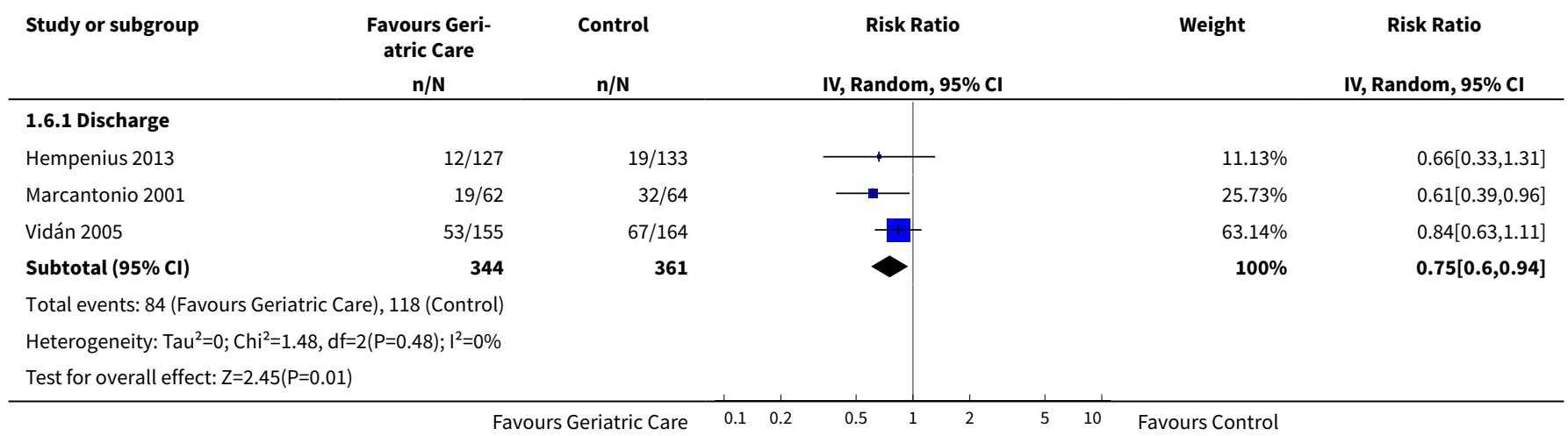

\section{APPENDICES}

\section{Appendix 1. Search strategies}

Last search conducted 13 January 2017

\section{MEDLINE, Ovid}

1. Geriatric Assessment/

2. geriatric assessment ${ }^{\star} . \mathrm{tw}, \mathrm{kf}$.

3. Health Services for the Aged/

4. or/1-3

5. comprehensive health care/

6. Patient Care Planning/

7. Progressive Patient Care/

8. patient care team/

9. patient-centered care/

10. "delivery of health care, integrated"/

11. or $/ 5-10$

12. (frail ${ }^{\star}$ or sarcopeni ${ }^{\star}$ or elder ${ }^{\star}$ or senior ${ }^{\star}$ or gerontolog* ${ }^{\star}$ or geriatric ${ }^{\star}$ or veteran ${ }^{\star}$ or (old ${ }^{\star}$ adj (people or person* or resident $^{\star}$ or adult $^{\star}$ or patient $\left.\left.{ }^{\star}\right)\right)$ ).tw,kf.

13. 11 and 12

14. limit 11 to "all aged (65 and over)"

15. 4 or 13 or 14

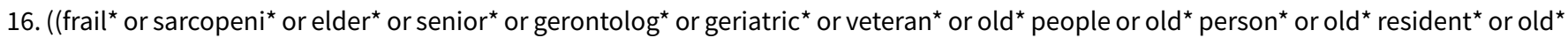
adult $^{\star}$ or old ${ }^{\star}$ patient ${ }^{\star}$ ) adj3 (assess ${ }^{\star}$ or evaluat* or apprais* or function or functioning or comprehensive* or patient care team or patient ${ }^{\star}$ education or interprofession* or inter-profession* or interdisciplin* or inter-disciplin* or multi-disciplin* or multidisciplin* or rehab*)).tw,kf.

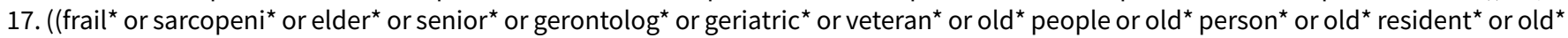
adult $^{\star}$ or old $^{\star}$ patient ${ }^{\star}$ ) adj3 (manage care program $^{\star}$ or Critical Pathway or Program $^{\star}$ Evaluation or case manag $)$ ).tw,kf.

18. (geriatric adj3 (evaluation or management or program ${ }^{\star}$ or modif* or friendly or intervention or coordinat ${ }^{\star}$ or co-ordinat $\left.^{\star}\right)$ ).tw, kf.

19. (elder ${ }^{\star}$ adj3 (program ${ }^{\star}$ or modif* or friendly or intervention $^{\star}$ or coordinat ${ }^{\star}$ or co-ordinat $\left.{ }^{\star}\right)$ ).tw,kf.

20. or/16-19

21. 15 or 20

22. exp Specialties, Surgical/

23. exp surgical procedures, operative/

24. su.fs.

25. Surgery Department, Hospital/

26. perioperative care/ or intraoperative care/ or perioperative nursing/ or postoperative care/ or preoperative care/

27. Trauma Centers/ or General Surgery/

28. (((surgery or surgical) adj (unit* or department ${ }^{\star}$ or area*)) or (operating adj (room or theatre or theater $^{\star}$ or suite $\left.)\right)$ ).mp.

29. (surgery or surgical or trauma or operation or operating or operative).ti.

30. (surgery or surgical or trauma or operation or operating or operative).kf.

31. (surgery or surgical or trauma or operation or operating or operative).ab. /freq=2 
32. (perioperative or peri operative or intraoperative or intra operative or postoperative or post-operative).ti,ab,kf.

33. or/22-32

34. (surgery or surgical or trauma or operation or operating or operative).mp.

35. hospital*.mp.

36.34 and 35

37.33 or 36

38. (acute care for elders or acute care for the elderly or Nurses Improving Care for Healthsystem Elders or modified Hospital Elder Life Program or mHELP or hospitali?ed elder life program*).tw,kf.

39. (geriatrician ${ }^{\star}$ or geriatric specialist ${ }^{\star}$ or geriatric nurse ${ }^{\star}$ or geriatric physician ${ }^{\star}$ ).tw,kf.

40. (geriatric unit* or geriatric ward $\left.{ }^{\star}\right) . t w, k f$.

41.39 or 40

42.37 and 41

43. 21 and 37

44. geriatric trauma*.mp.

45.42 or 43 or 44

46. randomised controlled trial.pt.

47. controlled clinical trial.pt.

48. multicenter study.pt.

49. pragmatic clinical trial.pt.

50. (randomis* or randomiz ${ }^{\star}$ or randomly).ti,ab.

51. groups.ab.

52. (trial or multicenter or multi center or multicentre or multi centre).ti.

53. (intervention? or effect? or impact? or controlled or control group? or (before adj5 after) or (pre adj5 post) or ((pretest or pre test) and (posttest or post test)) or quasiexperiment ${ }^{\star}$ or quasi experiment ${ }^{\star}$ or pseudo experiment ${ }^{\star}$ or pseudoexperiment ${ }^{\star}$ or evaluat $^{\star}$ or time series or time point? or repeated measur $\left.{ }^{\star}\right) . t i, a b$.

54. non-randomized controlled trials as topic/

55. interrupted time series analysis/

56. controlled before-after studies/

57. or/46-56

58. exp animals/

59. humans/

60. 58 not (58 and 59)

61. review.pt.

62. meta analysis.pt.

63. news.pt.

64. comment.pt.

65. editorial.pt.

66. cochrane database of systematic reviews.jn.

67. comment on.cm.

68. (systematic review or literature review).ti.

69. or $/ 60-68$

70.57 not 69

71.45 and 70

72. remove duplicates from 71

\section{Embase, Ovid}

1. geriatric assessment/

2. geriatric assessment ${ }^{\star} . \mathrm{tw}, \mathrm{kw}$.

3. elderly care/

4. geriatric care/

5. geriatric nursing/ or psychogeriatric nursing/

6. or/1-5

7. patient care planning/

8. progressive patient care/

9. 7 or 8

10. (frail ${ }^{\star}$ or sarcopeni ${ }^{\star}$ or elder ${ }^{\star}$ or senior $^{\star}$ or gerontolog* or geriatric or veteran $^{\star}$ or (old ${ }^{\star}$ adj (people or person* or resident ${ }^{\star}$ or adult $^{\star}$ or patient $\left.\left.t^{\star}\right)\right)$ ).tw,kw.

11. limit 9 to aged $<65+$ years $>$

12.9 and 10

13.6 or 11 or 12 


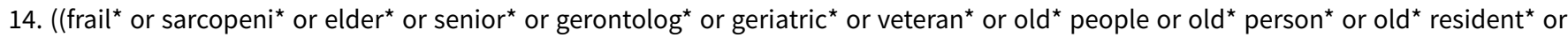
old $^{\star}$ adult $^{\star}$ or old patient $^{\star}$ ) adj3 (assess ${ }^{\star}$ or evaluat* or apprais* or function or functioning or comprehensive* or patient care team or disability evaluation or patient ${ }^{\star}$ education or interprofession* or inter-profession* or interdisciplin* or inter-disciplin* or multi-disciplin* or multidisciplin* or rehab*)).tw,kw.

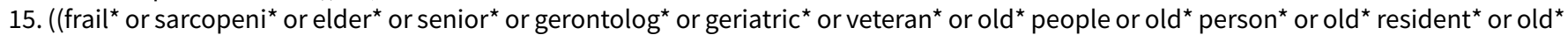
adult $^{\star}$ or old $^{\star}$ patient ${ }^{\star}$ ) adj3 (manage* care program ${ }^{\star}$ or Critical Pathway ${ }^{\star}$ or Program ${ }^{\star}$ Evaluation or case manag $\left.{ }^{\star}\right)$ ).tw,kw.

16. (geriatric adj3 (management or program* or modif* or friendly or intervention or coordinat* or co-ordinat ${ }^{\star}$ )).tw,kw.

17. (elder ${ }^{\star}$ adj3 (program* or modif* or friendly or intervention* ${ }^{\star}$ or coordinat* or co-ordinat $\left.{ }^{\star}\right)$ ).tw,kw.

18. or $/ 14-17$

19. 13 or 18

20. exp surgery/

21. (surgery or surgical or trauma or operation or operating or operative).ti,kw.

22. general surgery/

23. perioperative period/

24. intraoperative period/

25. perioperative nursing/

26. postoperative care/

27. preoperative care/ or preoperative period/

28. (((surgery or surgical) adj (unit* or department ${ }^{\star}$ or area*)) or (operating adj (room or theatre* or theater ${ }^{\star}$ or suite $\left.\left.)\right)\right) . t w, k w$.

29. (surgery or surgical or trauma or operation or operating or operative).ab. /freq=2

30. (perioperative or peri operative or intraoperative or intra operative or postoperative or post-operative).ti,kw.

31. (perioperative or peri operative or intraoperative or intra operative or postoperative or post-operative).ab. /freq=2

32. or $/ 20-31$

33. (surgery or surgical or trauma or operation or operating or operative).tw,kw.

34. hospital ${ }^{\star} . \mathrm{tw}, \mathrm{kw}$.

35.33 and 34

36. 32 or 35

37.19 and 36

38. (acute care for elders or acute care for the elderly or Nurses Improving Care for Healthsystem Elders or modified Hospital Elder Life Program or mHELP or hospitali?ed elder life program*).tw,kw.

39. (geriatrician* or geriatric specialist $^{\star}$ or geriatric nurse* or geriatric physician $\left.^{\star}\right) . \mathrm{mp}$.

40. (geriatric unit* or geriatric ward $\left.{ }^{\star}\right) \cdot \mathrm{mp}$.

41. or $/ 38-40$

42. 36 and 41

43. geriatric trauma*.mp.

44. 37 or 42 or 43

45. exp clinical trial/

46. exp controlled study/

47. (randomis* or randomiz* or randomly).ti,ab.

48. groups.ab.

49. (trial or multicenter or multi center or multicentre or multi centre).ti.

50. (intervention? or effect? or impact? or controlled or control group? or (before adj5 after) or (pre adj5 post) or ((pretest or pre test) and

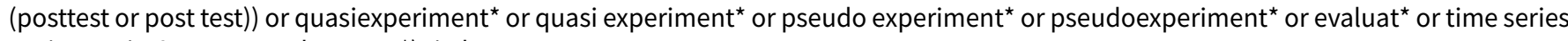
or time point? or repeated measur $\left.{ }^{\star}\right) . t i, a b$.

51. or/45-50

52. (exp vertebrate/ or animal/ or exp experimental animal/ or nonhuman/ or animal.hw.) not exp human/

53. "systematic review"/

54. "journal review".pt.

55. meta analysis/

56. cochrane database of systematic reviews.jn.

57. (systematic review or literature review).ti.

58. or $/ 52-57$

59. 51 not 58

60.44 and 59

61. remove duplicates from 60

\section{PsycINFO, Ovid}

1. geriatric assessment/

2. geriatric assessment ${ }^{\star} . \mathrm{mp}$.

3. 1 or 2

4. treatment planning/ or aftercare/ or posttreatment followup/ 
5. client centered therapy/

6. integrated services/ or interdisciplinary treatment approach/

7. or/4-6

8. (frail ${ }^{\star}$ or sarcopeni ${ }^{\star}$ or elder ${ }^{\star}$ or senior ${ }^{\star}$ or gerontolog ${ }^{\star}$ or geriatric $^{\star}$ or (old ${ }^{\star}$ adj (people or person ${ }^{\star}$ or resident $^{\star}$ or adult ${ }^{\star}$ or patient $\left.\left.^{\star}\right)\right)$ ).mp.

9. 7 and 8

10. limit 7 to "380 aged "

11.3 or 9 or 10

12. ((frail ${ }^{\star}$ or sarcopeni ${ }^{\star}$ or elder ${ }^{\star}$ or senior ${ }^{\star}$ or gerontolog ${ }^{\star}$ or geriatric ${ }^{\star}$ or old ${ }^{\star}$ people or old ${ }^{\star}$ person ${ }^{\star}$ or old resident $^{\star}$ or old $^{\star}$ adult $^{\star}$ or old $^{\star}$ patient ${ }^{\star}$ ) adj3 (assess ${ }^{\star}$ or evaluat ${ }^{\star}$ or apprais* or function or functioning or comprehensive* or patient care team or disability evaluation or patient ${ }^{\star}$ education or interprofession* or inter-profession* or interdisciplin ${ }^{\star}$ or inter-disciplin ${ }^{\star}$ or multi-disciplin ${ }^{\star}$ or multidisciplin ${ }^{\star}$ or rehab*)).mp.

13. ((frail ${ }^{\star}$ or sarcopeni ${ }^{\star}$ or elder ${ }^{\star}$ or senior ${ }^{\star}$ or gerontolog* or geriatric $^{\star}$ or old ${ }^{\star}$ people or old ${ }^{\star}$ person* or old $^{\star}$ resident $^{\star}$ or old $^{\star}$ adult $^{\star}$ or old $^{\star}$ patient ${ }^{\star}$ ) adj3 (manage* care program* or Critical Pathway* or Program* Evaluation or case manag $\left.{ }^{\star}\right)$ ).mp.

14. (geriatric adj3 (evaluation or management or program ${ }^{\star}$ or modif* or friendly or intervention or coordinat ${ }^{\star}$ or co-ordinat or $^{\star}$ ). $\mathrm{mp}^{*}$

15. (elder ${ }^{\star}$ adj3 (assess ${ }^{\star}$ or evaluation or program ${ }^{\star}$ or modif* or friendly or intervention $^{\star}$ or coordinat ${ }^{\star}$ or co-ordinat $\left.^{\star}\right)$ ).mp.

16. or/11-15

17. exp surgery/

18. (surgery or surgical or trauma or operation or operating or operative).mp.

19. surgical patients/

20. or/17-19

21. 16 and 20

22. (acute care for elders or acute care for the elderly or Nurses Improving Care for Healthsystem Elders or modified Hospital Elder Life Program or $\mathrm{mHELP}$ or hospitali?ed elder life program ${ }^{\star}$ ).mp.

23. (geriatrician* or geriatric specialist* or geriatric nurse ${ }^{\star}$ or geriatric physician $\left.{ }^{\star}\right) . \mathrm{mp}$.

24. (geriatric unit* or geriatric ward*).mp.

25. or/22-24

26. 20 and 25

27. geriatric trauma*.mp.

28. 21 or 26 or 27

29. control group/

30. random\$.mp.

31. (trial or multicenter or multi center or multicentre or multi centre).ti.32. ((singl\$ or doubl\$ or tripl\$ or trebl\$) adj10 (blind\$ or mask \$)).mp.

33. (cross?over or placebo $\$$ or control\$ or factorial or sham\$).mp.

34. (intervention? or effect? or impact? or controlled or control group? or (before adj5 after) or (pre adj5 post) or ((pretest or pre test) and (posttest or post test)) or quasiexperiment ${ }^{\star}$ or quasi experiment ${ }^{\star}$ or pseudo experiment ${ }^{\star}$ or pseudoexperiment ${ }^{\star}$ or evaluat $^{\star}$ or time series or time point? or repeated measur $\left.{ }^{\star}\right)$.ti,ab.

35. ((clin\$ or intervention $\$$ or compar\$ or experiment\$ or preventive or therap\$) adj10 (trial\$ or study or studies)).mp.

36. exp Experimentation/ or clinical research.mp. or exp Treatment Effectiveness Evaluation/

37. (follow adj2 study).mp. [mp=title, abstract, heading word, table of contents, key concepts, original title, tests \& measures]

38. (follow adj2 studies).mp. [mp=title, abstract, heading word, table of contents, key concepts, original title, tests \& measures]

39. or/29-38

40. 28 and 39

\section{Cochrane Central Register of Controlled Trials, Ovid EBMR}

2. geriatric assessment ${ }^{\star} . \mathrm{tw}, \mathrm{kf}$.

3. Health Services for the Aged/

4. or/1-3

5. comprehensive health care/

6. Patient Care Planning/

7. Progressive Patient Care/

8. patient care team/

9. patient-centered care/

10. "delivery of health care, integrated"/

11. or/5-10

12. (frail ${ }^{\star}$ or sarcopeni ${ }^{\star}$ or elder ${ }^{\star}$ or senior ${ }^{\star}$ or gerontolog* or geriatric $^{\star}$ or veteran ${ }^{\star}$ or (old ${ }^{\star}$ adj (people or person* or resident ${ }^{\star}$ or adult $^{\star}$ or patient $\left.\left.\left.{ }^{\star}\right)\right)\right) . \mathrm{tw}, \mathrm{kf}$.

13. 11 and 12

14. limit 11 to "all aged (65 and over)"

15.4 or 13 or 14 


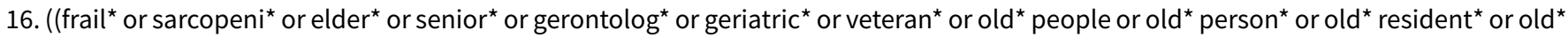
adult $^{\star}$ or old ${ }^{\star}$ patient ${ }^{\star}$ ) adj3 (assess ${ }^{\star}$ or evaluat* or apprais* or function or functioning or comprehensive* or patient care team or patient ${ }^{\star}$ education or interprofession* or inter-profession* or interdisciplin* or inter-disciplin* or multi-disciplin* or multidisciplin* or rehab $\left.{ }^{\star}\right)$ ).tw,kf. 17. ((frail ${ }^{\star}$ or sarcopeni ${ }^{\star}$ or elder ${ }^{\star}$ or senior $^{\star}$ or gerontolog* or geriatric $^{\star}$ or veteran ${ }^{\star}$ or old $^{\star}$ people or old person $^{\star}$ or old $^{\star}$ resident $^{\star}$ or old ${ }^{\star}$ adult $^{\star}$ or old ${ }^{\star}$ patient ${ }^{\star}$ ) adj3 (manage ${ }^{\star}$ care program ${ }^{\star}$ or Critical Pathway ${ }^{\star}$ or Program ${ }^{\star}$ Evaluation or case manag)).tw,kf.

18. (geriatric adj3 (management or program ${ }^{\star}$ or modif* or friendly or intervention or coordinat ${ }^{\star}$ or co-ordinat $\left.{ }^{\star}\right)$ ).tw,kf.

19. (elder* adj3 (program* or modif $^{\star}$ or friendly or intervention ${ }^{\star}$ or coordinat* or co-ordinat $\left.{ }^{\star}\right)$ ).tw,kf.

20. or/16-19

21. 15 or 20

22. exp Specialties, Surgical/

23. exp surgical procedures, operative/

24. su.fs.

25. Surgery Department, Hospital/

26. perioperative care/ or intraoperative care/ or perioperative nursing/ or postoperative care/ or preoperative care/

27. Trauma Centers/ or General Surgery/

28. (((surgery or surgical) adj (unit* or department $^{\star}$ or area*)) or (operating adj (room ${ }^{\star}$ or theatre* or theater $^{\star}$ or suite $\left.\left.\left.^{\star}\right)\right)\right)$.mp.

29. (surgery or surgical or trauma or operation or operating or operative).ti,kf.

30. (surgery or surgical or trauma or operation or operating or operative).ab. /freq=2

31. (perioperative or peri operative or intraoperative or intra operative or postoperative or post-operative).ti,ab,kf.

32. or/22-31

33. (surgery or surgical or trauma or operation or operating or operative).mp.

34. hospital*.mp.

35.33 and 34

36. 32 or 35

37. (acute care for elders or acute care for the elderly or Nurses Improving Care for Healthsystem Elders or modified Hospital Elder Life Program or mHELP or hospitali?ed elder life program ${ }^{\star}$ ).tw,kf.

38. (geriatrician or geriatric specialist* or geriatric nurse* or geriatric physician*).tw,kf.

39. (geriatric unit* or geriatric ward*).tw,kf.

40.38 or 39

41.36 and 40

42. 21 and 36

43. geriatric trauma*.mp.

44. 41 or 42 or 43

\section{CINAHL, EBSCOhost}

S1 (MH "Geriatric Assessment") OR (MH "Geriatric Functional Assessment")

S2 geriatric N2 assessment

S3 (MH "Health Services for the Aged")

\section{S4 S1 OR S2 OR S3}

S5 (MH "Multidisciplinary Care Team+") OR (MH "Patient Centered Care") OR (MH "Patient Care Plans+") OR (MH "Progressive Patient Care") OR (MH "Health Care Delivery, Integrated")

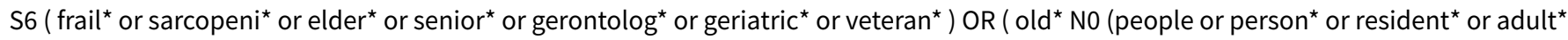
or patient $\left.{ }^{\star}\right)$ )

\section{S7 S5 AND S6}

S8 (MH "Multidisciplinary Care Team+") OR (MH "Patient Centered Care") OR (MH "Patient Care Plans+") OR (MH "Progressive Patient Care") OR (MH "Health Care Delivery, Integrated")

Limiters - Age Groups: Aged: 65+ years

\section{S9 S4 OR S7 OR S8}

S10 (frail ${ }^{\star}$ or sarcopeni ${ }^{\star}$ or elder ${ }^{\star}$ or senior ${ }^{\star}$ or gerontolog* or geriatric ${ }^{\star}$ or veteran ${ }^{\star}$ ) N3 (assess ${ }^{\star}$ or evaluat $^{\star}$ or apprais ${ }^{\star}$ or function or functioning or comprehensive*)

S11 (frail ${ }^{\star}$ or sarcopeni* or elder* or senior ${ }^{\star}$ or gerontolog* or geriatric* or veteran*) N3 ("patient care team" or "disability evaluation" or "patient* education" or interprofession* or "inter-profession*" or interdisciplin* or "inter-disciplin*" or "multi-disciplin*" or multidisciplin* or rehab*) 
S12 ("old* people" or "old* person" or "old* resident" or "old* adult*" or "old* patient*") N3 (assess" or evaluat* or apprais* or function or functioning or comprehensive*)

S13 (frail ${ }^{\star}$ or sarcopeni* or elder or senior $^{\star}$ or gerontolog* or geriatric ${ }^{\star}$ or veteran ${ }^{\star}$ ) N3 ("manage* care program*" or "Critical Pathway or "Program* Evaluation" or "case manag*)")

S14 ("old" people" or "old* person" or "old* resident*" or "old* adult*" or "old* patient*") N3 ("manage* care program" or "Critical Pathway*" or "Program* Evaluation" or "case manag*)")

S15 geriatric N3 (evaluation or management or program* or modif* or friendly or intervention or coordinat* or "co-ordinat*")

S16 elder* N3 (assess ${ }^{\star}$ or evaluation or program* or modif* or friendly or intervention* or coordinat* or "co-ordinat*")

S17 S10 OR S11 OR S12 OR S13 OR S14 OR S15 OR S16

S18 S9 OR S17

S19 (MH "Surgery, Operative+")

S20 (MH "Specialties, Surgical+") OR (MH "Medical-Surgical Nursing+")

S21 TI surgery or surgical or trauma or operation or operating or operative

S22 S19 OR S20 OR S21

S23 S18 AND S22

S24 "acute care for elders" or "acute care for the elderly" or "Nurses Improving Care for Healthsystem Elders" or "modified Hospital Elder Life Program" or mHELP or "hospitalized elder life program*" or "hospitalised elder life program*"

S25 ( geriatrician* or "geriatric specialist*" or "geriatric nurse*" or "geriatric physician*" ) OR "geriatric unit* "or "geriatric ward*"

\section{S26 S24 OR S25}

S27 S22 AND S26

S28 "geriatric trauma"

S29 S23 OR S27 OR S28

S30 (MH "Clinical Trials+")

S31 PT Clinical trial

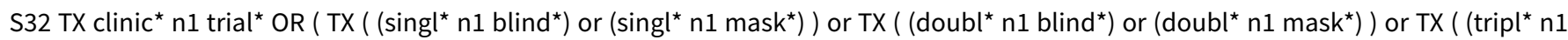
blind $\left.^{\star}\right)$ or $\left(\operatorname{tripl}^{\star} \mathrm{n} 1\right.$ mask $\left.^{\star}\right)$ ) or TX ( (trebl* $n 1$ blind $\left.{ }^{\star}\right)$ or $\left(\operatorname{trebl}^{\star} \mathrm{n} 1\right.$ mask $\left.\left.^{\star}\right)\right)$ ) OR TX randomi ${ }^{\star}$ control $^{\star}$ trial $^{\star}$

S33 (MH "Random Assignment")

S34 TX random* allocat*

S35 TX placebo*

S36 (MH "Placebos") OR (MH "Quantitative Studies")

S37 TX allocat* random* $^{*}$

S38 (MH "Controlled Before-After Studies") OR (MH "Interrupted Time Series Analysis")

S39 ( controlled or "control group*" ) OR before W5 after OR pre W5 post OR ( quasiexperiment* or "quasi experiment*" or "pseudo experiment ${ }^{\star}$ or pseudoexperiment* or "time series" or "time point" or "repeated measur*" )

S40 ( pretest or "pre test" ) AND ( posttest or "post test" )

S41 S30 OR S31 OR S32 OR S33 OR S34 OR S35 OR S36 OR S37 OR S38 OR S39 OR S40

S42 S29 AND S41

Comprehensive geriatric assessment for older people admitted to a surgical service (Review) 
S43 systematic review or meta-analysis or literature review

S44 S42 NOT S43

Appendix 2. GRADE evidence profile geriatric care versus usual care for older adult surgical patients

Author: Eamer G, Tacheri A, Chen SS, Daviduck Q, Champers T, Shi X, Khadaroo RG

Date: 13 January 2017

Question: Geriatric Care compared to Control for older people admitted to a surgical service

Setting: Acute hospital or rehabilitation hospital following acute admission for surgical intervention

Bibliography: Eamer G, Taheri A, Chen SS, Daviduck Q, Chambers T, Khadaroo RG. Comprehensive geriatric assessment for older people admitted to a surgical service. Cochrane Database of Systematic Reviews [Year], Issue [Issue]. 


\begin{tabular}{|c|c|c|c|c|c|c|c|c|c|c|c|c|}
\hline \multicolumn{7}{|c|}{ Quality assessment } & \multicolumn{2}{|c|}{ № of participants } & \multicolumn{2}{|l|}{ Effect } & \multirow[t]{2}{*}{ Quality } & \multirow{2}{*}{$\begin{array}{l}\text { Impor- } \\
\text { tance }\end{array}$} \\
\hline $\begin{array}{l}\text { № of } \\
\text { studies }\end{array}$ & $\begin{array}{l}\text { Study } \\
\text { design }\end{array}$ & $\begin{array}{l}\text { Risk of } \\
\text { bias }\end{array}$ & $\begin{array}{l}\text { Incon- } \\
\text { sistency }\end{array}$ & $\begin{array}{l}\text { Indirect- } \\
\text { ness }\end{array}$ & $\begin{array}{l}\text { Impreci- } \\
\text { sion }\end{array}$ & $\begin{array}{l}\text { Other } \\
\text { consid- } \\
\text { erations }\end{array}$ & $\begin{array}{l}\text { Geri- } \\
\text { atric } \\
\text { care }\end{array}$ & Control & $\begin{array}{l}\text { Relative } \\
(95 \% \mathrm{CI})\end{array}$ & $\begin{array}{l}\text { Absolute } \\
(95 \% \mathrm{Cl})\end{array}$ & & \\
\hline \multicolumn{13}{|c|}{ Mortality } \\
\hline 5 & $\begin{array}{l}\text { Ran- } \\
\text { domised } \\
\text { trials }\end{array}$ & $\begin{array}{l}\text { Not seri- } \\
\text { ous }\end{array}$ & $\begin{array}{l}\text { Not seri- } \\
\text { ous }\end{array}$ & $\begin{array}{l}\text { Not seri- } \\
\text { ous }\end{array}$ & Seriousa & None & $\begin{array}{l}119 / 666 \\
(17.9 \%)\end{array}$ & $\begin{array}{l}139 / 65 \\
(21.4 \%)\end{array}$ & $\begin{array}{l}\text { RR } 0.85 \\
(0.68 \text { to } \\
1.05)\end{array}$ & $\begin{array}{l}32 \text { fewer per } 1000 \\
\text { (from } 11 \text { more to } 68 \\
\text { fewer) }\end{array}$ & $\begin{array}{l}\oplus \oplus \oplus \bigcirc \\
\text { MODER- } \\
\text { ATE }\end{array}$ & CRITICAL \\
\hline \multicolumn{13}{|c|}{ Discharge to an increased level of care } \\
\hline 5 & $\begin{array}{l}\text { Ran- } \\
\text { domized } \\
\text { trials }\end{array}$ & $\begin{array}{l}\text { Not seri- } \\
\text { ous }\end{array}$ & $\begin{array}{l}\text { Not seri- } \\
\text { ous }\end{array}$ & $\begin{array}{l}\text { Not seri- } \\
\text { ous }\end{array}$ & $\begin{array}{l}\text { Not seri- } \\
\text { ous }\end{array}$ & None & $\begin{array}{l}84 / 484 \\
(17.4 \%)\end{array}$ & $\begin{array}{l}113 / 45 \\
(24.7 \%)\end{array}$ & $\begin{array}{l}\mathbf{R R} \mathbf{0 . 7 1} \\
(0.55 \text { to } \\
0.92)\end{array}$ & $\begin{array}{l}\mathbf{7 2} \text { fewer per } 1000 \\
\text { (from } 20 \text { fewer to } 111 \\
\text { fewer) }\end{array}$ & $\begin{array}{l}\oplus \oplus \oplus \oplus \\
\mathrm{HIGH}\end{array}$ & CRITICAL \\
\hline \multicolumn{13}{|c|}{ Length of stay } \\
\hline 4 & $\begin{array}{l}\text { Ran- } \\
\text { domized } \\
\text { trials }\end{array}$ & $\begin{array}{l}\text { Not seri- } \\
\text { ous }\end{array}$ & Serious $b$ & $\begin{array}{l}\text { Not seri- } \\
\text { ous }\end{array}$ & $\begin{array}{l}\text { Not seri- } \\
\text { ous }\end{array}$ & None & 440 & 401 & - & $\begin{array}{l}\text { MD } 1.47 \text { days less } \\
\text { (2.8 less to } 0.14 \text { less) }\end{array}$ & $\begin{array}{l}\oplus \oplus \oplus O \\
\text { MODER- } \\
\text { ATE }\end{array}$ & $\begin{array}{l}\text { IMPOR- } \\
\text { TANT }\end{array}$ \\
\hline \multicolumn{13}{|c|}{ Re-admission } \\
\hline 3 & $\begin{array}{l}\text { Ran- } \\
\text { domized } \\
\text { trials }\end{array}$ & $\begin{array}{l}\text { Not seri- } \\
\text { ous }\end{array}$ & $\begin{array}{l}\text { Not seri- } \\
\text { ous }\end{array}$ & $\begin{array}{l}\text { Not seri- } \\
\text { ous }\end{array}$ & Serious a & None & $\begin{array}{l}116 / 368 \\
(31.5 \%)\end{array}$ & $\begin{array}{l}118 / 37 \\
(31.6 \%)\end{array}$ & $\begin{array}{l}\text { RR 1.00 } \\
(0.76 \text { to } \\
1.32)\end{array}$ & $\begin{array}{l}\text { 0 fewer per } 1000 \\
\text { (from } 76 \text { fewer to } 101 \\
\text { more) }\end{array}$ & $\begin{array}{l}\oplus \oplus \oplus O \\
\text { MODER- } \\
\text { ATE }\end{array}$ & $\begin{array}{l}\text { IMPOR- } \\
\text { TANT }\end{array}$ \\
\hline \multicolumn{13}{|c|}{ Total cost } \\
\hline 1 & $\begin{array}{l}\text { Ran- } \\
\text { domized } \\
\text { trials }\end{array}$ & $\begin{array}{l}\text { Not seri- } \\
\text { ous }\end{array}$ & $\begin{array}{l}\text { Not seri- } \\
\text { ous }\end{array}$ & $\begin{array}{l}\text { Not seri- } \\
\text { ous }\end{array}$ & $\begin{array}{l}\text { Not seri- } \\
\text { ous }\end{array}$ & $\begin{array}{l}\text { Incom- } \\
\text { plete } \\
\text { mea- } \\
\text { sure- } \\
\text { ment of } \\
\text { cost c }\end{array}$ & 198 & 199 & - & $\begin{array}{l}\text { MD EUR } 5154 \text { less } \\
\text { (13,288.06 lower to } \\
2980.06 \text { higher) }\end{array}$ & $\begin{array}{l}\oplus \oplus \oplus O \\
\text { MODER- } \\
\text { ATE }\end{array}$ & $\begin{array}{l}\text { IMPOR- } \\
\text { TANT }\end{array}$ \\
\hline \multicolumn{13}{|c|}{ Major complication } \\
\hline
\end{tabular}




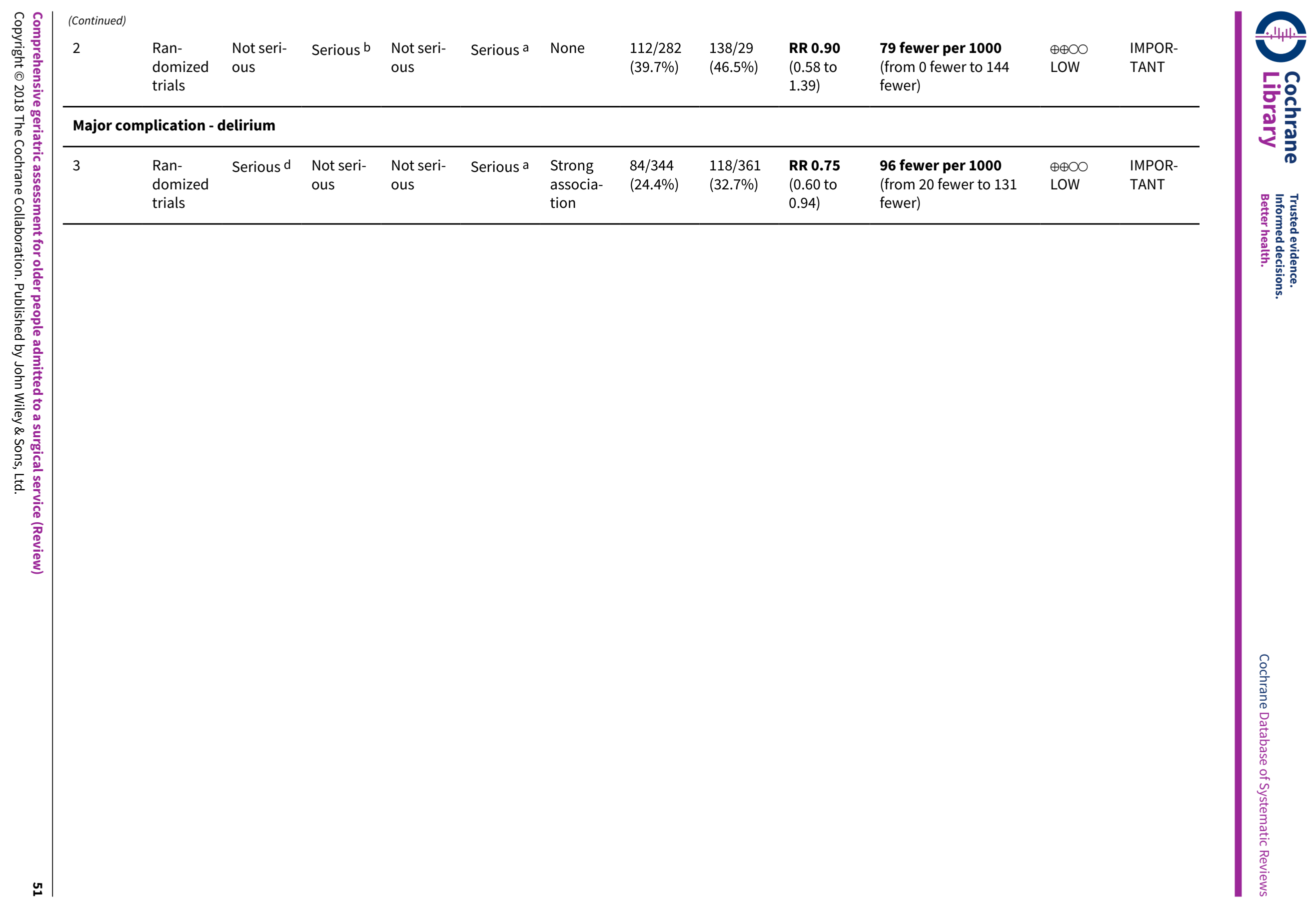


Cl: Confidence interval; RR: Risk ratio; MD: Mean difference. Footnotes a: There are wide confidence intervals that include both no effect and a high risk of benefit or harm. b: There was significant variability between studies for this outcome. c: Costing was calculated in an imprecise manner (costs are presented as the total cost over one year, however the admission cost did not include rehabilitation hospital costs despite the authors identifying a higher proportion of control patients being transferred to rehabilitation centres before discharge). d: Risk of bias in assessment of outcome in one study.

WHAT'S NEW

\begin{tabular}{lll}
\hline Date & Event & Description \\
\hline 14 March 2018 & Amended & $\begin{array}{l}\text { Removal of duplicate rows appearing in Hempenius 2013 Risk of } \\
\text { bias table }\end{array}$ \\
\hline
\end{tabular}

\section{CONTRIBUTIONS OFAUTHORS}

QD and GE coordinated the contributions from the co-authors. QD, SC, TC, and GE worked on the methods sections. QD and GE drafted the clinical sections of the background, and TC was the contract person with the editorial base. QD and GE wrote the protocol with assistance from AT, SC, RK, and TC. TC devised and carried out the search strategy. QD, GE, and SC wrote the statistical analysis and data synthesis sections. RK, SC, QD, GE, and AT contributed significantly to the review. XS provided guidance for statistical analysis. Abstracts, results, discussion and conclusions were written by GE. Editing and revision of these sections was performed by the remainder of the team.

\section{DECLARATIONS OF INTEREST}

Gilgamesh Eamer: none known.

Amir Taheri: none known.

Sidian S Chen: none known.

Quinn Daviduck: none known.

Thane Chambers: none known.

Xinzhe Shi: none known.

Rachel G Khadaroo: none known.

\section{SOURCES OF SUPPORT}

\section{Internal sources}

- University of Alberta, Canada.

Salary support for: AT, TC, RK

\section{External sources}

- Canadian Frailty Network, Canada.

Canadian Frailty Network Interdisciplinary Fellowship 2016 for: GE

- Alberta Innovates Health Solutions, Canada.

AlHS Summer studentship for: QD

\section{DIFFERENCES BETWEEN PROTOCOLANDREVIEW}

We performed minimal subgroup analysis due to the small number of included trials. We were unable to assess comprehensive geriatric assessment (CGA) timing and emergency versus elective subgroup analyses. We performed surgical specialty subgroup analyses by excluding the non-orthopedic study from analysis. We were unable to perform sensitivity analysis by bias due to the small number of low risk studies reporting each outcome. We were also unable to assess publication bias by constructing funnel plots, also due to the small number of included trials. We did not identify any cluster randomised trials for inclusion, so did not experience any unit of analysis issues. There were low attrition rates in all included studies, so we did not impute any missing data. We attempted to contact study authors who 
we felt may have had more data, but the time elapsed since may included studies were completed meant that few additional data were available.

\section{NOTES}

This review is based on standard text and guidance provided by the Cochrane Effective Practice and Organisation of Care (EPOC) Group.

\section{NDEX TERMS}

\section{Medical Subject Headings (MeSH)}

*Geriatric Assessment; *Length of Stay; Delirium [epidemiology]; Elective Surgical Procedures [mortality]; Hip Fractures [mortality] [ ${ }^{\star}$ surgery]; Neoplasms [mortality] [ ${ }^{\star}$ surgery]; Patient Readmission [statistics \& numerical data]; Postoperative Complications [epidemiology]; Randomized Controlled Trials as Topic; Treatment Outcome

\section{MeSH check words}

Aged; Humans 